\title{
Impact of the South China Sea Summer Monsoon on the Indian Ocean Dipole
}

\author{
YAZHOU ZHANG \\ College of Global Change and Earth System Science, Beijing Normal University, Beijing, China \\ JIANPING LI \\ College of Global Change and Earth System Science, Beijing Normal University, Beijing, and Laboratory for Regional Oceanography \\ and Numerical Modeling, Qingdao National Laboratory for Marine Science and Technology, Qingdao, China
}

\section{JIAQING XUE}

State Key Laboratory of Numerical Modeling for Atmospheric Sciences and Geophysical Fluid Dynamics, Institute of Atmospheric Physics, Chinese Academy of Sciences, and College of Earth Science, University of Chinese Academy of Sciences, Beijing, China

\author{
JuAN FENG, QIUYUn WANG, YIDAN XU, AND YUEHONG WANG \\ College of Global Change and Earth System Science, Beijing Normal University, Beijing, China
}

FEI ZHENG

State Key Laboratory of Numerical Modeling for Atmospheric Sciences and Geophysical Fluid

Dynamics, Institute of Atmospheric Physics, Chinese Academy of Sciences, Beijing, China

(Manuscript received 1 December 2017, in final form 25 May 2018)

\begin{abstract}
This paper investigates the impact of the South China Sea summer monsoon (SCSSM) on the Indian Ocean dipole (IOD). The results show that the SCSSM has a significant positive relationship with the IOD over the boreal summer [June-August (JJA)] and fall [September-November (SON)]. When the SCSSM is strong, the enhanced southwesterly winds that bring more water vapor to the western North Pacific (WNP) lead to surplus precipitation in the WNP, inducing anomalous ascending there. Consequently, the anomalous descending branch of the SCSSM Hadley circulation (SCSSMHC) develops over the Maritime Continent (MC), favoring deficit precipitation in situ. The precipitation dipole over the WNP and MC as well as the enhanced SCSSMHC leads to intensification of the southeasterly anomalies off Sumatra and Java, which then contributes to the negative sea surface temperature (SST) anomalies through the positive wind-evaporation-SST and wind-thermocline-SST (Bjerknes) feedbacks. Consequently, a positive IOD develops because of the increased zonal gradient of the tropical Indian Ocean SST anomalies and vice versa. The SCSSM has a peak correlation with the IOD when the former leads the latter by three months. This implies that a positive IOD can persist from JJA to SON and reach its mature phase within the frame of the positive Bjerknes feedback in SON. In addition, the local and remote SST anomalies in the tropical Indian and Pacific Oceans have a slight influence on the relationship between the SCSSM and precipitation dipole over the WNP and MC.
\end{abstract}

\section{Introduction}

The Indian Ocean dipole (IOD) is a prominent coupled air-sea phenomenon related to interannual variability in the tropical Indian Ocean that reveals opposite episodes of sea surface temperature (SST) anomalies

Corresponding author: Dr. Jianping Li, ljp@bnu.edu.cn
(SSTAs) in the tropical southeastern Indian Ocean and western Indian Ocean (Saji et al. 1999; Webster et al. 1999). Other climate variables (e.g., subsurface sea temperature, sea level, sea surface salinity, and outgoing longwave radiation anomalies) show a somewhat similar mode in both observations and models, implying the physical nature of the IOD (Feng and Meyers 2003; Saji and Yamagata 2003; Masson et al. 2004; Shinoda et al. 
2004; Spencer et al. 2005; Grunseich et al. 2011; Zhang et al. 2016). IOD events have a significant influence on the climate in the Indian Ocean rim countries, as well as across East Asia and the Southern Hemisphere through teleconnection (Guan and Yamagata 2003; Ding et al. 2008; Li et al. 2011a,b; Nuncio and Yuan 2015). To better understand IOD variability and influence mechanisms of the IOD on climate and to predict the IOD, it is necessary to investigate the impact factors of the IOD and relevant mechanisms.

In general, the IOD appears in boreal late spring [March-May (MAM)], develops in boreal summer [June-August (JJA)], and peaks in boreal autumn [September-November (SON)] with the demise in boreal winter [December-February (DJF)], showing remarkable seasonal phase locking (Saji et al. 1999; Webster et al. 1999). More studies have demonstrated that the strong southeasterly wind anomalies off Sumatra and Java can directly enhance surface evaporation and coastal upwelling in situ during JJA and further result in the cooling of SST via the wind-evaporation-SST (WES) and wind-thermocline-SST (Bjerknes) feedbacks (Behera et al. 1999; Xie et al. 2002; Kajikawa et al. 2003; Xiang et al. 2011). In the mature phase of the IOD, the equatorial easterly wind anomalies play the dominant role in the maturation of the IOD via the positive Bjerknes feedback (Saji et al. 1999; Webster et al. 1999; Ashok et al. 2003; Li et al. 2003). These demonstrate that the southeasterly/easterly wind off Sumatra and Java is essential for the formation of the IOD.

Previous studies indicated that the IOD can be influenced by El Niño-Southern Oscillation (ENSO) through the Walker circulation (Klein et al. 1999; Xie et al. 2002; Stuecker et al. 2017), while others suggested that the IOD is an inherent mode in the tropical Indian Ocean (Saji et al. 1999; Webster et al. 1999; Behera et al. 2006). Longterm numerical simulations showed that the large-scale atmospheric circulations of the IOD with ENSO are different from the IOD without ENSO (Lau and Nath 2004; Fischer et al. 2005; Fan et al. 2017; Stuecker et al. 2017). In addition, some studies have reported that there exists a relationship between the Asian summer monsoon and the IOD (Ashok et al. 2001; Li and Mu 2001; Saji and Yamagata 2003; Yuan et al. 2008; Yang et al. 2010; Xiang et al. 2011). Most of them focused on the influence of the IOD on the Asian summer monsoon (Ashok et al. 2001; Saji and Yamagata 2003; Yang et al. 2010). For example, Ashok et al. (2001) investigated the modulation of the IOD on the relationship between the Indian summer monsoon and ENSO. Yuan et al. (2008) examined the influence of the IOD on the South China Sea (SCS) summer monsoon (SCSSM) in the following year. At present, however, there are few studies on the impact of the summer monsoon on the IOD.

In terms of the onset and evolution of the IOD from the point of view of monsoonal circulation, some studies indicated that the Asian monsoonal circulation could provide a favorable state for the development of the IOD (Annamalai et al. 2003; Xiang et al. 2011). For instance, Annamalai et al. (2003) emphasized the potential role of the background summer monsoon circulation in the development of the IOD. Xiang et al. (2011) indicated that the boreal summer warm mean state in the tropical southeastern Indian Ocean is important for the rapid development of the IOD through the enhanced equatorial easterly wind anomalies. Krishnan and Swapna (2009) pointed out that a positive IOD would favor an intensified summer monsoon circulation and the strengthened Indian summer monsoon could further strengthen the IOD. However, these studies mainly focus on the role of the Indian summer monsoon in the IOD development, and there is insufficient attention given to other summer monsoons, for example, the SCSSM.

$\mathrm{Li}$ and $\mathrm{Mu}$ (2001) pointed out that a positive (negative) IOD corresponds to a strong (weak) SCSSM, implying the link between the IOD and the SCSSM, while the impact of the SCSSM on the IOD and the underlying physical mechanism, as well, were not investigated. As is known, the SCSSM, as a prominent climate variability over the SCS, is a monsoon system that consists of different components over the SCS and western North Pacific (WNP), such as monsoonal circulations, intensive convection and precipitation, SCSSM Hadley circulation (SCSSMHC), and water vapor transport ( $\mathrm{Li}$ and Zeng 2002, 2003; Wang et al. 2009). For the strong SCSSM, the enhanced precipitation over the WNP corresponds to the suppressed precipitation over the Maritime Continent (MC; Li and Zeng 2002, 2003). Kajikawa et al. (2003) indicated that the negative SSTAs and suppressed convection first appeared off Sumatra in July, and convection over the WNP was enhanced, which led to the intensified local Hadley circulation over the western Pacific, and consequently, the strengthening of southeasterlies followed to the coast of Sumatra, which plays a role in triggering the zonally asymmetric anomalies over the tropical Indian Ocean in the following autumn. However, what are possible causes of the enhanced convection over the WNP and suppressed convection over the MC? Which one of two convection anomalies over the WNP and MC is first? Through diagnostic analysis, we find that the SCSSM plays an important role in the convection anomalies over the WNP and MC and then further influences the IOD development. Thus, this study aims to investigate the impact of the SCSSM on the IOD and relevant physical processes 
and mechanisms in JJA. In the process of the SCSSM affecting the IOD, we examine the possible cause and effect between the precipitation dipole and the SCSSMHC over the WNP and MC and also illustrate the bridges of the precipitation dipole and the SCSSMHC in the relationship between the SCSSM system and the IOD. In addition, the roles of the local SSTAs over the WNP and $\mathrm{MC}$ and remote SSTAs from the tropical Indian and Pacific Oceans in the relationship between the SCSSM system and the IOD are also discussed.

The remainder of this paper is organized as follows: The datasets used in this study are described in section 2 , and section 3 describes the relationship between the SCSSM and IOD. Section 4 investigates the roles of the precipitation dipole and the SCSSMHC over the WNP and $\mathrm{MC}$ in the relationship of the SCSSM system with the IOD, and the underlying physical mechanisms. Section 5 provides a discussion of the roles of local and remote SSTAs from the tropical Indian and Pacific Oceans in the relationship between the SCSSM system and the IOD. Finally, we summarize our findings in section 6 .

\section{Data}

Monthly mean wind fields at 12 vertical levels (1000$100 \mathrm{hPa}$ ), 10-m wind fields, sea level pressure (SLP), latent heat flux, and precipitation rate data were taken from the National Centers for Environmental PredictionNational Center for Atmospheric Research (NCEPNCAR) reanalysis dataset (Kalnay et al. 1996) for the period of 1948-2015. Meanwhile, the weekly mean data calculated by the daily wind fields and precipitation rate derived from NCEP-NCAR are used to discuss the possible cause and effect between the SCSSMHC and the precipitation dipole. The SST data for the same period were obtained from the Hadley Centre Sea Ice and SST dataset (Rayner et al. 2003). The sea surface height (SSH) data were obtained from the Simple Ocean Data Assimilation (SODA, version 2.2.4) reanalysis dataset on a $0.5^{\circ} \times 0.5^{\circ}$ grid for the period of 1948-2010 and were used as a proxy for variability in the thermocline (Carton and Giese 2008). In addition, monthly mean precipitation from the Climate Prediction Center Merged Analysis of Precipitation (CMAP) product for the period of 1979-2015 (Xie and Arkin 1997) was used as a proxy for large-scale convective activity and also to validate the precipitation rate calculated using the NCEP-NCAR data. The grid resolution of the wind, SLP, latent heat flux, and precipitation data was $2.5^{\circ} \times 2.5^{\circ}$, and that of SST data was $1^{\circ} \times 1^{\circ}$ longitude-latitude. A linear trend and the monthly mean climatology were removed from each dataset.
The SCSSM index (SCSSMI) in this paper is taken from the seasonally dynamical normalized seasonality index, which is defined by Li and Zeng $(2002,2003)$. The seasonally dynamical normalized seasonality index based on the intensity of the seasonal wind field is used to capture the seasonal cycle and interannual variability of global monsoon regions ( $\mathrm{Li}$ et al. 2010; Zhu et al. 2012; Feng et al. 2015; Huyan et al. 2017; Liu et al. 2018). Its intensity is given by

$$
\delta=\frac{\left\|\overline{\mathbf{V}}_{1}-\mathbf{V}_{m, n}\right\|}{\|\overline{\mathbf{V}}\|}-2,
$$

where $\overline{\mathbf{V}}_{1}$ and $\overline{\mathbf{V}}$ are the January climatological wind vectors and the mean of January and July climatological wind vectors at a point, respectively, and $\mathbf{V}_{m, n}$ is the monthly wind vectors in the $m$ th month of the $n$th year. The SCSSMI is defined as an area-averaged seasonally dynamical normalized seasonality at the $925-\mathrm{hPa}$ wind field in JJA within the SCS monsoon domain $\left(100^{\circ}-\right.$ $\left.125^{\circ} \mathrm{E}, 0^{\circ}-25^{\circ} \mathrm{N}\right)$.

The Niño-3.4 index, calculated from the SSTAs area averaged over the equatorial central Pacific $\left(5^{\circ} \mathrm{S}-5^{\circ} \mathrm{N}\right.$, $120^{\circ}-170^{\circ} \mathrm{W}$ ), is used to describe ENSO. We use the dipole mode index (DMI) as defined by Saji et al. (1999), which is the difference in SSTAs between the west pole $\left(50^{\circ}-70^{\circ} \mathrm{E}, 10^{\circ} \mathrm{S}-10^{\circ} \mathrm{N}\right)$ and the east pole $\left(90^{\circ}-110^{\circ} \mathrm{E}\right.$, $\left.10^{\circ} \mathrm{S}-0^{\circ}\right)$. The statistical significance of the results was tested using Student's $t$ test.

\section{Relationship between the SCSSM and the IOD}

To explore the relationship of the SCSSM with the JJA and SON IOD, Fig. 1a shows the correlation coefficients between the SCSSMI and the seasonally averaged DMI for the period of 1948-2015. The results indicate that the relationship between the SCSSM and the IOD is insignificant in MAM, features a significant correlation in JJA, reaches a maximum in SON, and decreases rapidly during DJF. A comparison of the SCSSMI and SON DMI shows that the correlation coefficient $R$ reaches 0.57 , which is beyond the $99 \%$ confidence level (Fig. 1b). These results suggest that the SCSSM is closely related to the IOD.

To further investigate the relationship between the SCSSM and the IOD, Fig. 2 shows correlation maps of the SCSSMI with the tropical Indian Ocean SSTAs from MAM to DJF. For the strong SCSSM, the negative correlations spread across the whole Indian Ocean basin in MAM, indicating that the cold SSTAs are dominant in the tropical Indian Ocean (Fig. 2a). In the following season, positive correlations replace the significant negative correlations in the western central Indian Ocean, 

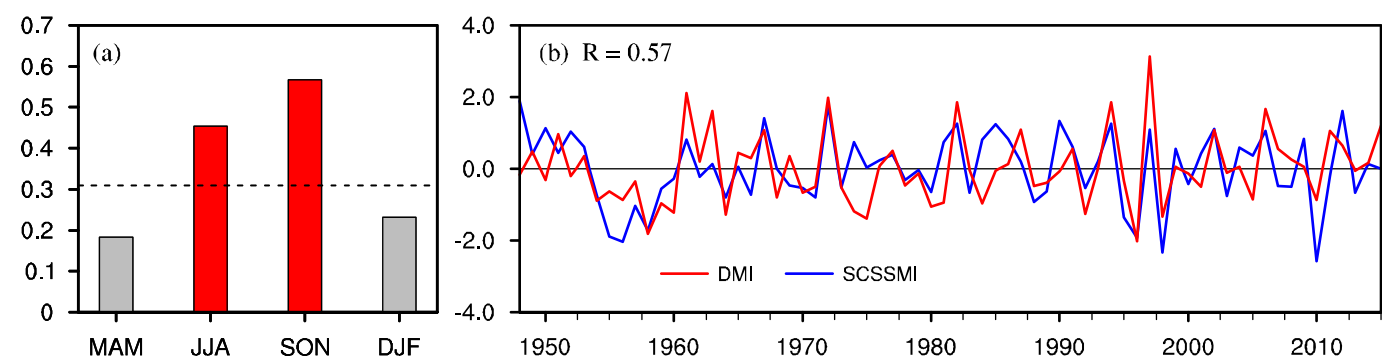

FIG. 1. (a) Correlation coefficients between the seasonally averaged Indian Ocean DMI from MAM to DJF and SCSSMI (JJA) during 1948-2015. The dashed line indicates exceeding the 99\% confidence level. (b) Standardized time series of the JJA SCSSMI (blue line) and SON DMI (red line). The correlation coefficient $R$ between them is 0.57 , beyond the $99 \%$ confidence level (Student's $t$ test).

and this is followed by an increase in the negative correlations in the tropical southeastern Indian Ocean (Fig. 2b). The cold SSTAs intensify and appear to migrate toward the equator along the Sumatra-Java coastline, while SSTAs over the tropical western central Indian Ocean begin to warm up. The opposite sign of SSTAs tends to form in the tropical Indian Ocean. The warmerthan-normal SSTAs extend from the tropical central Indian Ocean to the western Indian Ocean, accompanied by an enhancement of the cold SSTAs in the tropical southeastern Indian Ocean, which indicates a dramatic peaking of these features in SON (Fig. 2c). The positive correlations are significant from SON to DJF in the tropical western central Indian Ocean, but the negative correlations over the tropical southeastern Indian Ocean weaken and become insignificant in DJF (Fig. 2d), suggesting that the SSTAs dipole fades away, followed by the demise of the cold SSTAs in the tropical southeastern Indian Ocean during DJF. The seasonal evolution of the tropical Indian Ocean SSTAs associated with the SCSSM is similar to the feature described by Saji et al. (1999), who used composite analysis to reveal the bimonthly evolution of the positive IOD. We also selected the 21 anomalous SCSSM events (13 strong SCSSM and 8 weak SCSSM) to calculate the composite anomalies based on the strong SCSSM minus the weak SCSSM. When
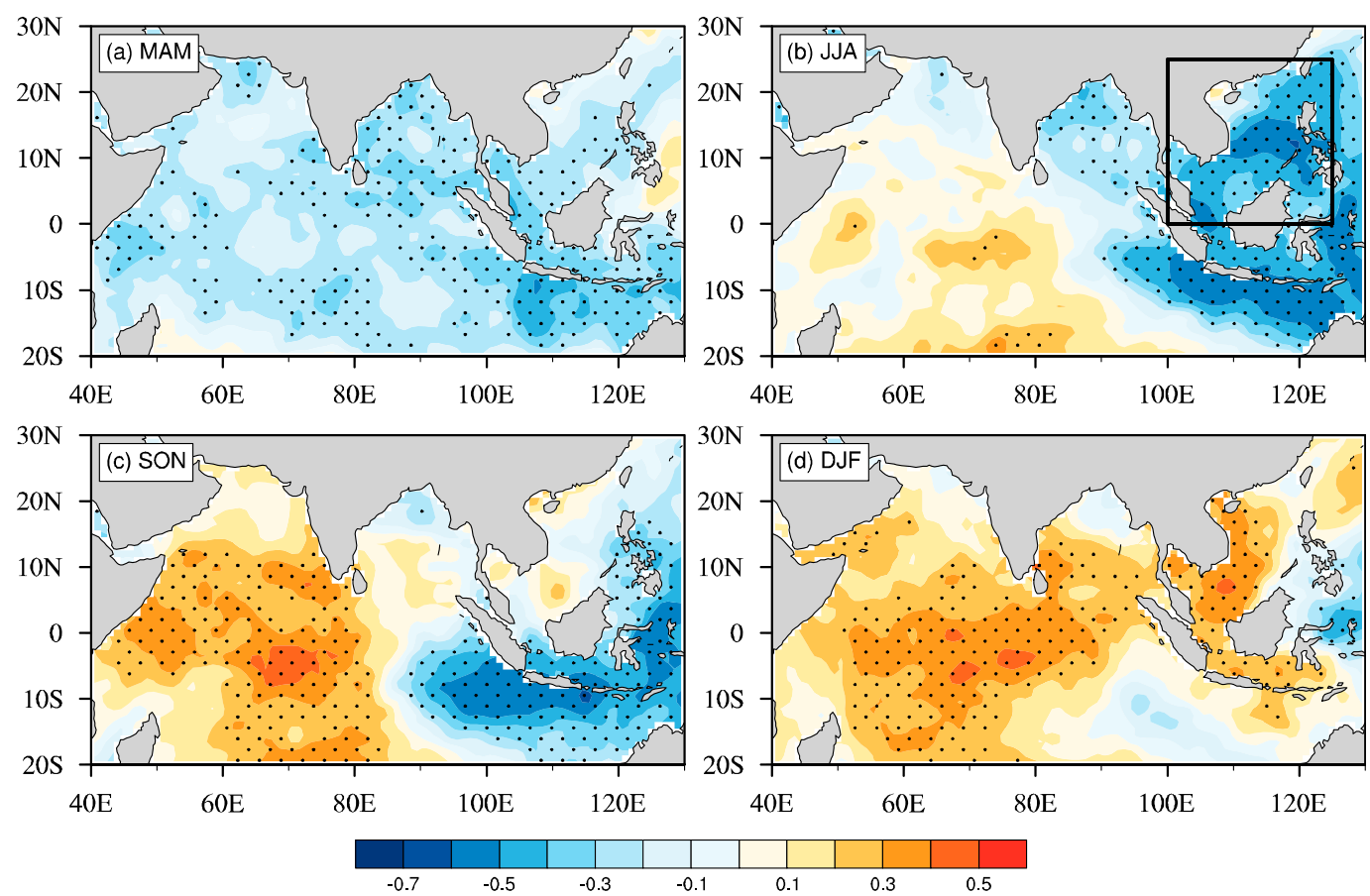

FIG. 2. Correlations of the SCSSMI with SSTAs (shading) in (a) MAM, (b) JJA, (c) SON, and (d) DJF during 1948-2015. The black rectangle in (b) denotes the SCSSM region $\left(100^{\circ}-125^{\circ} \mathrm{E}, 0^{\circ}-25^{\circ} \mathrm{N}\right)$. Black stipples in (a)-(d) indicate the $95 \%$ confidence level. 


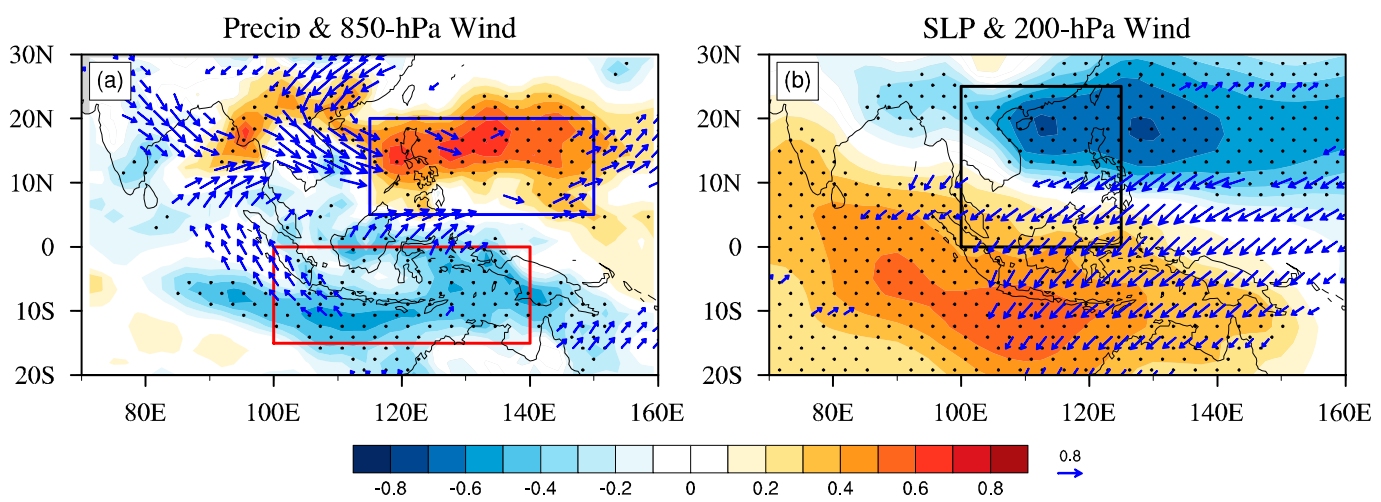

FIG. 3. (a) Correlations of the SCSSMI with JJA precipitation (shading) and wind anomalies (vectors) at $850 \mathrm{hPa}$ during 1948-2015; (b) as in (a), but for the JJA SLP (shading) and 200-hPa wind anomalies. The blue (red) rectangles in (a) denote the regions over the WNP $\left(115^{\circ}-150^{\circ} \mathrm{E}, 5^{\circ}-20^{\circ} \mathrm{N}\right)$ and $\mathrm{MC}\left(100^{\circ}-140^{\circ} \mathrm{E}, 15^{\circ} \mathrm{S}-0^{\circ}\right)$, respectively. The black rectangle in (b) is as in Fig. 2 b to denote the SCSSM region. Black stipples in (a) and (b) indicate the $95 \%$ confidence level. Only wind vectors that are significant at the $90 \%$ confidence level are plotted.

SCSSM is strong, the IOD begins to form with the increased zonal gradient of SSTAs over the tropical Indian Ocean in JJA and peaks in SON with more remarkable warming in the tropical western Indian Ocean accompanied by the demise of SSTAs in the tropical southeastern Indian Ocean (not shown). These results agree with the correlation maps shown in Fig. 2. Our temporal and spatial results show that the dipole-like pattern of the SSTAs over the tropical Indian Ocean is significantly correlated with the SCSSM from JJA to SON. However, the correlations give no indication of cause and effect. Hence, we will explore a possible physical linkage between the SCSSM and the IOD in the following section.

\section{Physical linkage between the SCSSM and the IOD}

\section{a. Precipitation dipole and SCSSMHC related to the SCSSM}

How does the SCSSM affect the IOD? To answer this question, Fig. 3 shows the correlations between the SCSSMI and the simultaneous precipitation, SLP, and lower- and upper-level wind anomalies. Significant positive correlations between the SCSSM and precipitation anomalies appear in the WNP, and significant negative correlations occur in the MC, which means surplus precipitation in the WNP and deficit precipitation in the MC when the SCSSM is strong (Fig. 3a). The WNP and MC precipitation dipole pattern (PMPD, where "PM" denotes the WNP and MC, respectively) is also found in the CMAP precipitation data for 1979-2015 (not shown), indicating the development of anomalous convective activity. Correspondingly, the anomalous lowerlevel convergence in the WNP and divergence in the
MC, but at a weakened intensity, induce the SLP anomalies to decrease over the WNP and increase over the MC (Fig. 3b). The increased south-north SLP gradient between the WNP and $\mathrm{MC}$ results in an anomalous lower-level southerly wind prevailing from the MC to the WNP. The anomalous southerly wind originating in the $\mathrm{MC}$ to the north of the equator, induced by the Coriolis force, penetrates northeastward, whereas the anomalous southerly wind off Sumatra and Java, which is induced by the Coriolis force, turns into an anomalous southeasterly wind and shifts westward after crossing the equator (Fig. 3a). In the upper-level troposphere, the anomalous northeasterly wind extends from the WNP to the MC (Fig. 3b). The PMPD develops over the WNP and MC, together with northward lower-level wind anomalies originating in the MC (Fig. 3a) and southward upper-level wind anomalies originating in the WNP (Fig. 3b), suggesting an anomalous local Hadley circulation between the WNP and the MC. This result is also verified in Fig. 4a, which indicates the presence of an anomalous local Hadley circulation in the verticalmeridional circulation averaged between $90^{\circ}$ and $150^{\circ} \mathrm{E}$. An anomalous ascending limb of the anomalous local Hadley circulation is located at roughly $20^{\circ} \mathrm{N}$ and contributes to the enhanced precipitation over the WNP. Meanwhile, the suppressed precipitation anomalies in the MC tend to intensify because of the anomalous descending motion near $10^{\circ} \mathrm{S}$. Figure $4 \mathrm{~b}$ shows the mean climatology of the local Hadley circulation between $90^{\circ}$ and $150^{\circ} \mathrm{E}$ in $\mathrm{JJA}$. The ascending branches of the local Hadley circulation are in the Northern Hemisphere between $0^{\circ}$ and $30^{\circ} \mathrm{N}$, and the descending branches are in the Southern Hemisphere between $10^{\circ}$ and $30^{\circ} \mathrm{S}$. Superimposed on the JJA-mean climatology (Fig. 4b), the anomalous upward (downward) motion in the WNP 

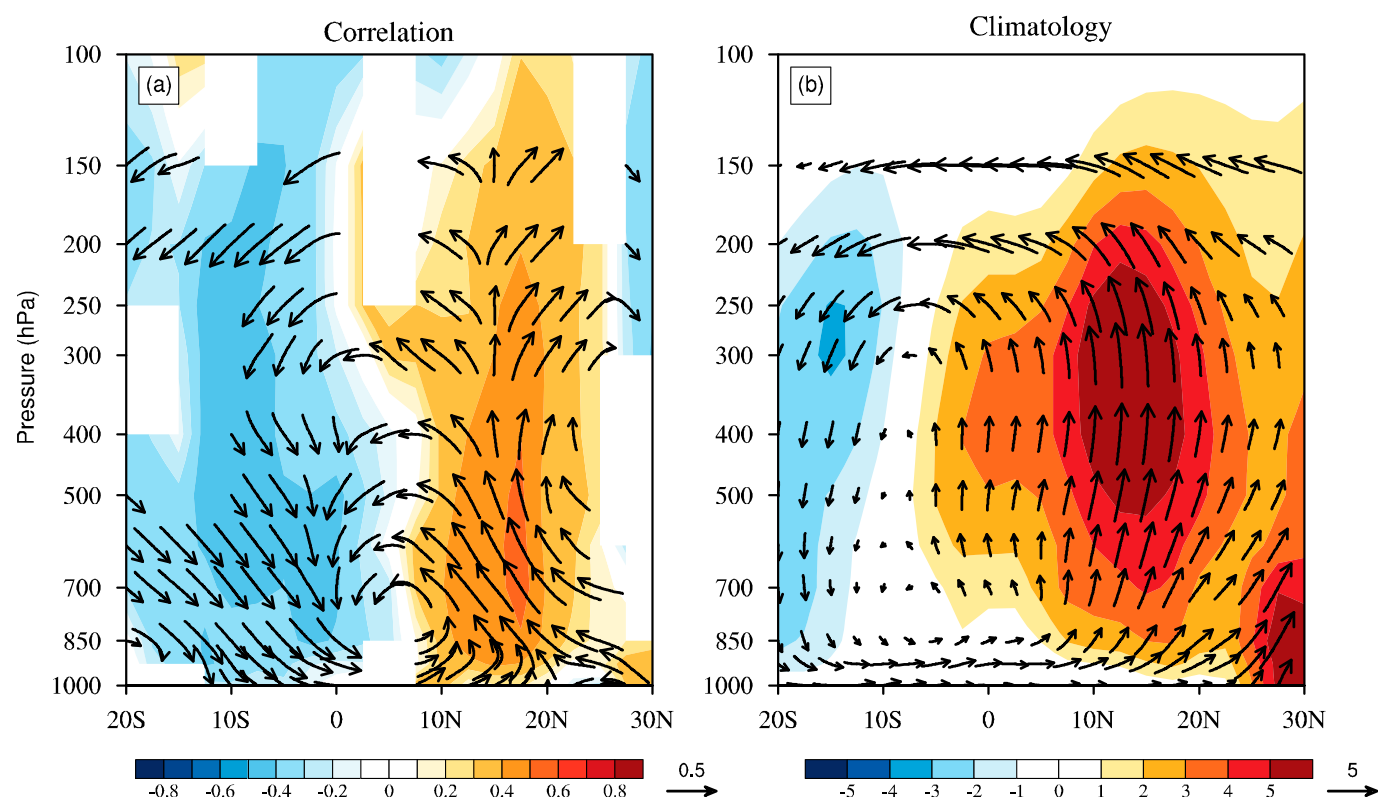

FIG. 4. (a) Correlations of the SCSSMI with JJA meridional-vertical circulation anomalies averaged between $90^{\circ}-150^{\circ} \mathrm{E}$ (vectors) and vertical velocity anomalies (shading). The shading is only shown when the values are significant at the $95 \%$ confidence level; red and orange (blue) colors represent ascending (descending). (b) The JJA-mean climatology of the meridional-vertical circulation.

(MC) in turn strengthens the local Hadley circulation when the SCSSM is strong and vice versa.

This anomalous SCSSMHC develops over the WNP and MC, which is closely associated with the SCSSM. Consequently, we define the SCSSMHC index (SCSSMHCI) as the difference in meridional velocity anomalies between the upper troposphere (250$150 \mathrm{hPa})$ and lower troposphere $(1000-850 \mathrm{hPa})$ over the region $\left(100^{\circ}-150^{\circ} \mathrm{E}, 20^{\circ} \mathrm{S}-20^{\circ} \mathrm{N}\right)$. To ensure the stability of the SCSSMHCI, we select the 3 levels averaged (250, 200 , and $150 \mathrm{hPa}$, as well as 1000,925 , and $850 \mathrm{hPa}$ ) meridional velocity anomalies to denote the upper- and lower-troposphere mean meridional wind, respectively. We also obtained a similar result using the difference in the meridional velocity anomalies between 200 and $850 \mathrm{hPa}$ (not shown). To further investigate the relationship between the SCSSMHC and the anomalous PMPD, we also define the anomalous PMPD index (PMPDI) as the difference between the area-averaged precipitation anomalies in the WNP $\left(115^{\circ}-150^{\circ} \mathrm{E}\right.$, $\left.5^{\circ}-20^{\circ} \mathrm{N}\right)$ and $\mathrm{MC}\left(100^{\circ}-140^{\circ} \mathrm{E}, 15^{\circ} \mathrm{S}-0^{\circ}\right)$, which are shown in Fig. 3a.

Figure 5 shows the standardized time series of the SCSSMI, JJA SCSSMHCI, and JJA PMPDI. The correlation coefficient between the SCSSMI and JJA PMPDI is 0.77 (significant at the $99 \%$ level), suggesting more precipitation over the WNP and less precipitation over the MC for a strong SCSSM event. The correlation

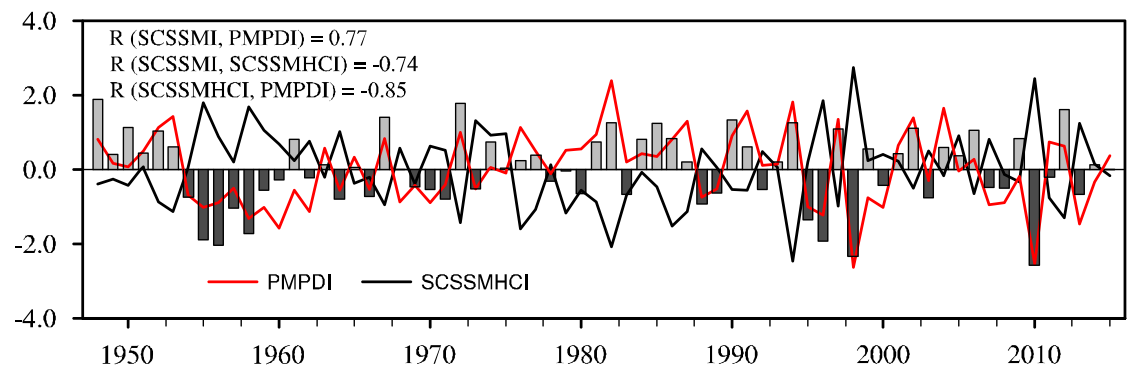

FIG. 5. Standardized time series of the SCSSMI (bars), JJA SCSSMHCI (black line), and PMPDI (red line) during 1948-2015. The correlation coefficient $R$ of the SCSSMI with JJA PMPDI and SCSSMHCI is 0.77 and -0.74 , respectively. The correlation coefficient $R$ is -0.85 between the PMPDI and the SCSSMHCI in JJA. All correlation coefficients are beyond the $99 \%$ confidence level. 
(a) SCSSMI \& SCSSMHCI

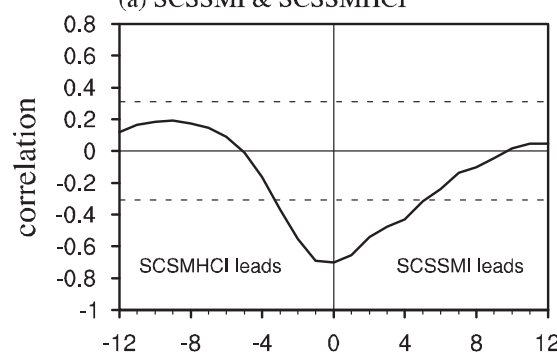

(d) SCSSMI \& DMI

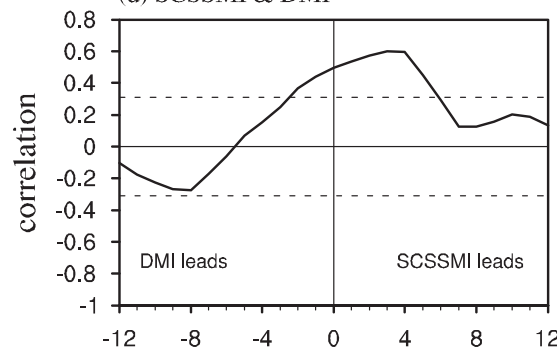

(g) PMPDI \& WNPI

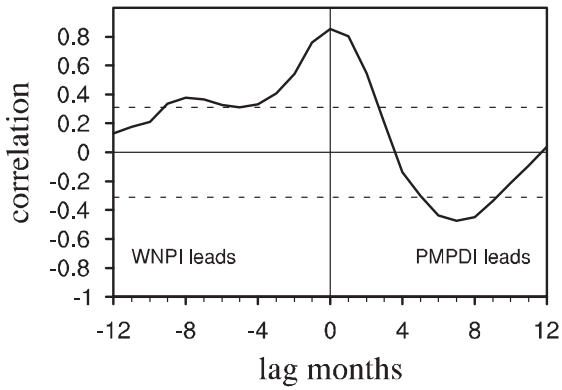

(b) SCSSMI \& PMPDI

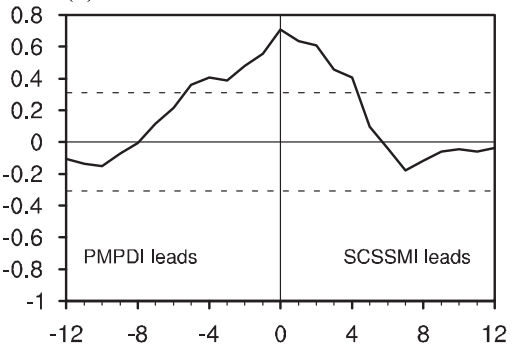

(e) SCSSMHCI \& DMI

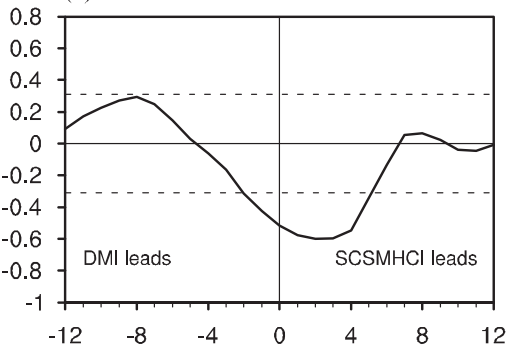

(h) PMPDI \& MCI

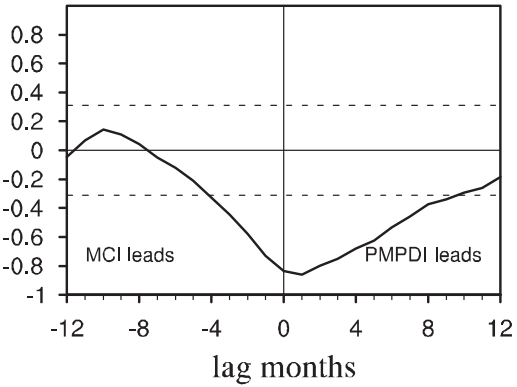

(c) SCSSMHCI \& PMPDI

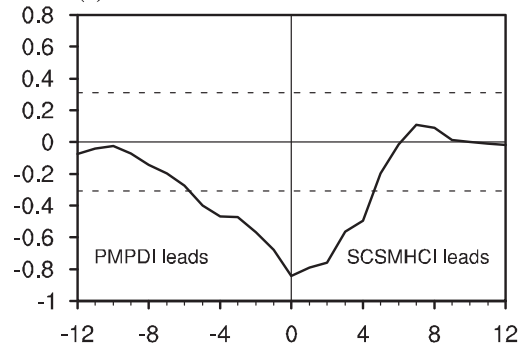

(f) PMPDI \& DMI

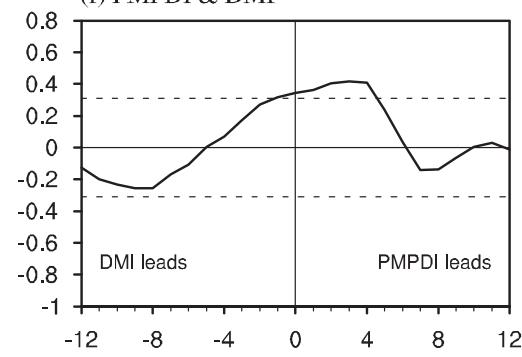

(i) WNPI \& MCI

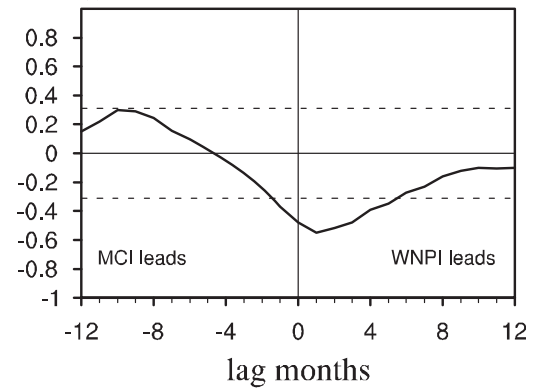

FIG. 6. Lead-lag correlations between two different indices. (a) The SCSSMI and SCSSMHCI, (b) the SCSSMI and PMPDI, (c) the PMPDI and SCSSMHCI, (d) the SCSSMI and DMI, (e) the SCSSMHCI and DMI, (f) the PMPDI and DMI, (g) PMPDI and WNPI, (h) PMPDI and MCI, and (i) WNPI and MCI. Here, the WNPI is area averaged over the WNP $\left(5^{\circ}-20^{\circ} \mathrm{N}, 115^{\circ}-150^{\circ} \mathrm{E}\right)$ with precipitation, the $\mathrm{MCI}$ is as for the WNPI, but for the $\mathrm{MC}\left(15^{\circ} \mathrm{S}-0^{\circ}, 100^{\circ}-140^{\circ} \mathrm{E}\right)$. All indices have been 3-month averaged. The dashed line indicates the $95 \%$ confidence level.

between the SCSSMI and JJA SCSSMHCI is negative and significant above the $99 \%$ confidence level with a value of -0.74 , demonstrating the intensification of the ascending motion in the WNP and the descending motion in the MC when the SCSSM is strong. The significant correlation between the PMPDI and the SCSSMHCI in JJA ( -0.85 , significant at the $99 \%$ level) also illustrates the close relationship between surplus precipitation associated with the upward motion in the WNP and deficit precipitation associated with the downward motion in the MC. In addition, the IOD exhibits two significant spectrum peaks: quasi-biennial and 5-6-yr periods ( $\mathrm{Li}$ and $\mathrm{Mu} 2001$ ). The power spectra of JJA SCSSMI, SCSSMHCI, and PMPDI have the significant quasi-biennial peak (not shown), in accordance with one mean peak (quasi-biennial periods) of the IOD. The coherence spectrum analysis further illustrates that the quasi-biennial periods are significant among the JJA
SCSSMI, PMPDI, SCSSMHCI, and DMI (not shown). These suggest that the IOD is closely linked to the SCSSM, PMPD, and SCSSMHC.

\section{b. Roles of the SCSSMHC and anomalous PMPD in the relationship between the SCSSM and the IOD}

Since the SCSSM is highly related to the SCSSMHC and PMPD in JJA, what roles do the PMPD and SCSSMHC play in the relationship between the SCSSM and the IOD? Figure 6 shows the lead-lag correlations between pairs of indices among the SCSSMI, PMPDI, SCSSMHCI, and DMI. In this plot, the month with a lag of 0 denotes the peak season of the SCSSM (JJA), and the maximum correlations of the SCSSMI with the PMPDI (Fig. 6a) and SCSSMHCI (Fig. 6b) are both at a lag of 0 , showing the simultaneous response of the anomalous PMPD and the SCSSMHC to the SCSSM. Figure $6 \mathrm{c}$ shows the lead-lag correlation between the 
(a) SCSSMI \& SCSSMHCI

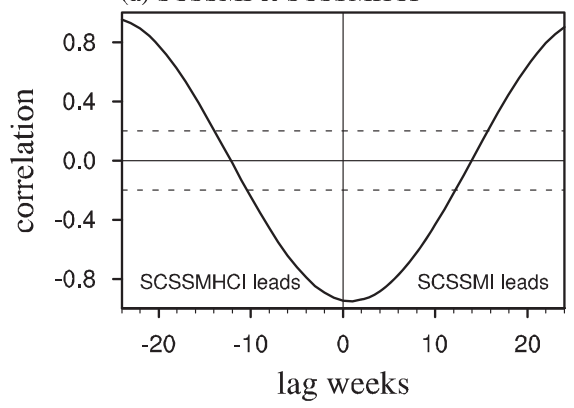

(b) SCSSMI \& PMPDI

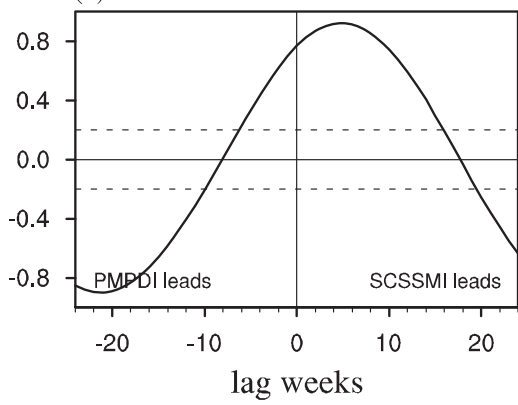

(c) SCSSMHCI \& PMPDI

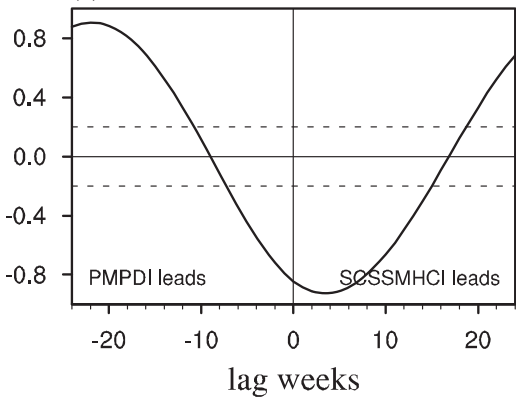

FIG. 7. As in Figs. 6a-c, but for the weekly mean data.

SCSSMHCI and PMPDI, which indicates that the SCSSMHC changes synchronously with the anomalous PMPD. The IOD is significantly delayed to the SCSSM by 3 months (Fig. 6d), which is in agreement with the maximum correlation between the SCSSM and SON IOD (Fig. 1b). The SCSSMHC leads the IOD by 23 months (Fig. 6e), indicating that the SCSSMHC affects the IOD. The PMPDI leading the DMI by 3 months indicates the influence of the anomalous PMPD on the IOD (Fig. 6f). These results demonstrate that the SCSSM, PMPD, and SCSSMHC have significant impacts on the IOD. In addition, the precipitation anomalies over the WNP and MC form the PMPD, while the question of which one of the two convection anomalies over the WNP and MC is first is unclear. The lead-lag correlations among the PMPDI, WNP index (WNPI), and MC index (MCI) are shown in Figs. 6g-i. Here, the WNPI is area averaged over the $\mathrm{WNP}\left(5^{\circ}-20^{\circ} \mathrm{N}, 115^{\circ}-150^{\circ} \mathrm{E}\right)$ with precipitation, and the $\mathrm{MCI}$ is the same as WNPI but for the MC $\left(15^{\circ} \mathrm{S}-0^{\circ}, 100^{\circ}-140^{\circ} \mathrm{E}\right)$. The PMPDI has a significant peak correlation with the WNPI at the lag month of 0 in Fig. $6 \mathrm{~g}$, indicating the PMPD changing synchronously with the convection anomalies over the WNP. The PMPDI and WNPI lead the MCI by 1 month, which demonstrates the convection anomalies over the WNP can affect the convection anomalies over the MC (Figs. 6h,i).

The SCSSM, SCSSMHC, and PMPD denoting the circulation or precipitation (convection) features are the different expressions of the SCSSM system. This implies that the different components of the SCSSM system may have different evolutions in time. Although the SCSSM changes simultaneously with the SCSSMHC and PMPD by monthly mean data, it does not mean that they show the same signals in finer temporal resolution data. The weekly mean data calculated from daily data, thus, are applied in Fig. 7, which shows the lead-lag correlations among the SCSSMI, SCSSMHCI, and PMPDI. The 9 weeks running are calculated to suppress the transient disturbance of the SCSSM, SCSSMHC, and PMPD. The maximum correlation between the SCSSMI and the SCSSMHCI occurs when the former leads the latter by 1 week (Fig. 7a). This indicates that the SCSSM affects the SCSSMHC. Figure 7b shows the SCSSMI has a peak correlation with the PMPDI when the former leads the latter by 5 weeks, suggesting that the PMPD is delayed to the SCSSM. The PMPD lagging the SCSSMHC by about 3 weeks means the former is influenced by the latter (Fig. 7c). In addition, the SCSSMI leads the WNPI by the weekly mean data based on the lead-lag correlation (not shown). Those results can be summarized as follows: For the strong SCSSM, the cold SSTAs over the WNP in MAM and JJA are not favorable for enhanced precipitation (Figs. 2a,b), while the westerly/southwesterly wind anomalies that bring a great amount of moisture are favorable for enhanced precipitation over the WNP (not shown). This implies that the SCSSM is prior to the precipitation over the WNP. The increased latent heat with the decrease of the SLP anomalies because of the enhanced precipitation over the WNP induces the anomalous ascending motion there (Fig. $4 \mathrm{a}$ ), contributing to the enhancement of the SCSSMHC. Consequently, the anomalous descending branch of the SCSSMHC develops over the MC, leading to the suppressed precipitation over the MC (Fig. 4a). Because of the southwesterly wind anomalies over the SCS being strengthened by the increased gradient of the precipitation anomalies between the WNP and the MC, the SCSSM is further enhanced, which in turn promotes the development of the SCSSMHC and the PMPD. It is suggested that the SCSSM can affect the SCSSMHC and PMPD, corresponding with the intensive feedback to the development of the SCSSM.

Therefore, we propose the hypothesis that a bridging mechanism between the SCSSM and the IOD is the SCSSMHC and PMPD. To validate this hypothesis, Table 1 lists the partial correlation coefficients between the SCSSMI and JJA DMI for the period 1948-2015. The correlation coefficient between the SCSSMI and JJA DMI reaches 0.46 (significant at the $99 \%$ level), but 
TABLE 1. The partial correlation coefficients of the SCSSMI with JJA and SON DMI during 1948-2015. The season in brackets denotes the averaged season of the different index, i.e., Rm-Niño3.4 (Pre-DJF) indicates the removal of the preceding boreal winter ENSO signals. The asterisk indicates the $99 \%$ confidence level.

\begin{tabular}{lcccccc}
\hline \hline & & \multicolumn{3}{c}{ Partial correlation } \\
\cline { 3 - 6 } & Correlation & $\begin{array}{c}\text { Rm-SCSSMHCI } \\
(J J A)\end{array}$ & $\begin{array}{c}\text { Rm-PMPDI } \\
(J J A)\end{array}$ & $\begin{array}{c}\text { Rm-Niño-3.4 } \\
\text { (Pre-DJF) }\end{array}$ & $\begin{array}{c}\text { Rm-Niño-3.4 } \\
\text { (Pre-MAM) }\end{array}$ & $\begin{array}{c}\text { Rm-Niño-3.4 } \\
(J J A)\end{array}$ \\
\hline (SCSSMI, JJA-DMI) & $0.46^{*}$ & 0.1 & 0.21 & $0.44^{*}$ & $0.46^{*}$ & $0.4^{*}$ \\
(SCSSMI, SON-DMI) & $0.57^{*}$ & & & $0.56^{*}$ & $0.6^{*}$ & $0.5^{*}$ \\
\hline
\end{tabular}

falls to 0.1 (statistically insignificant) after removal of the JJA SCSSMHC signal. Similarly, the correlation of the SCSSMI with JJA DMI is not significant, with a value of 0.21 , after removing the signal of the JJA PMPD. These results indicate the key roles of both the PMPD and SCSSMHC in bridging the SCSSM and the IOD, which is consistent with our hypothesis.

\section{c. Physical mechanism of influence of the SCSSM on the IOD}

As noted above, we will now investigate the physical processes that underlie the effect of the SCSSM on the IOD. When the SCSSM is strong, the enhanced southeasterly/ westerly wind anomalies that bring large amounts of moisture are favorable for surplus precipitation in the WNP, resulting in the increased latent heat with a decrease of the SLP anomalies (Fig. 3b), and favoring the formation of the positive heating source. According to the asymmetric Gill theory (Gill 1980; Xing et al. 2014), an anomalous lower-level cyclone with great surface convergence forms over the WNP in response to the positive heating source (Figs. 8a,c), and an anomalous anticyclone with great divergence forms in the upper levels (Figs. 8b,d). Similarly, deficit precipitation with surface divergence occurs in the $\mathrm{MC}$, reducing the latent heat with the increase of the SLP anomalies (Figs. 8a,c). The suppressed precipitation contributes to the formation of the negative heating source. The anomalous lower-level anticyclone (Fig. 8a) and anomalous upper-level cyclone (Fig. 8b) develop over the MC as a response to the
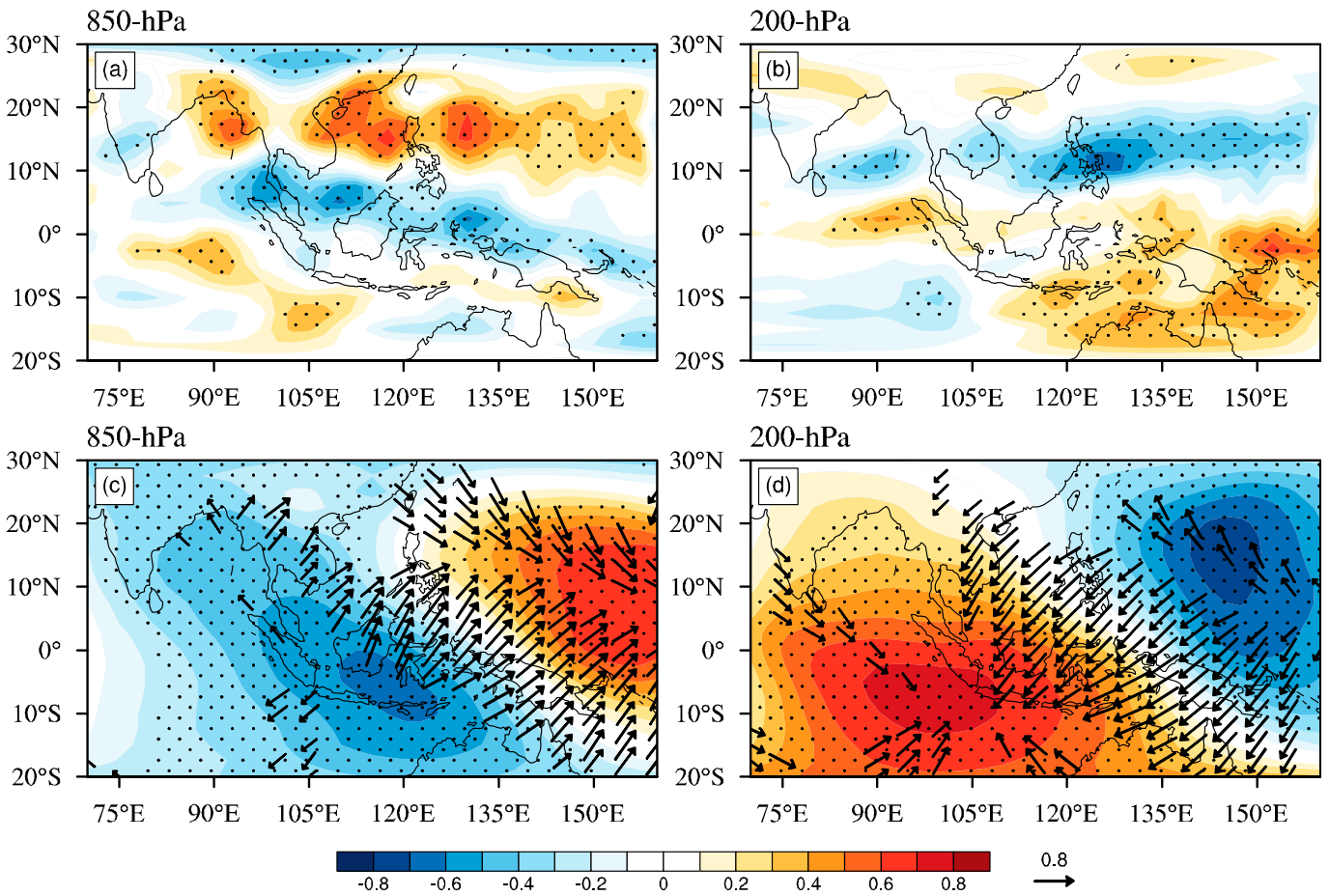

FIG. 8. The correlations of the SCSSMI with $850-\mathrm{hPa}$ (a) vorticity (shading) and (c) velocity potential (shading) and corresponding divergent winds anomalies (vectors); (b),(d) as in (a) and (c), but for $200 \mathrm{hPa}$. Black stipples in (a)-(d) indicate the $95 \%$ confidence level. Only wind vectors in (c) and (d) that are significant at the $95 \%$ confidence level are plotted. 

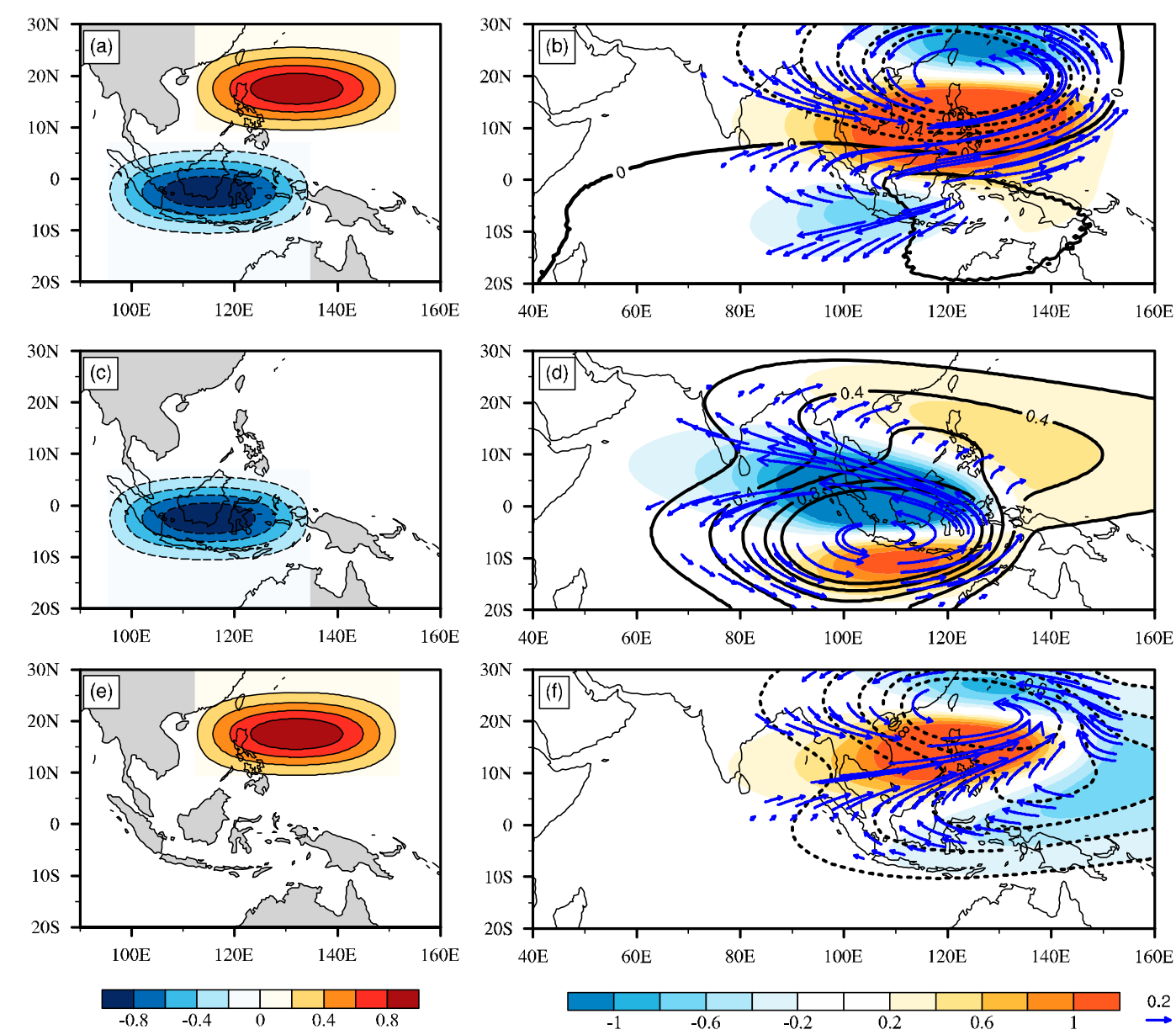

FIG. 9. (a) The location of the heating dipole over the WNP and MC in the Gill model. (b) The Gill-type response of the pressure (contour; $\mathrm{hPa}$ ), zonal wind (shading; $\mathrm{m} \mathrm{s}^{-1}$ ), and lower-level wind (blue vectors; $\mathrm{m} \mathrm{s}^{-1}$ ) to the heating dipole. (c),(e) As in (a) and (d),(f) as in (b), but for the isolated negative heating source over the MC and positive heating source over the WNP. Both the zonal and meridional wind speeds exceeding $0.05 \mathrm{~m} \mathrm{~s}^{-1}$ are plotted.

negative heating source. The PMPD, combined with the configuration of the significant convergence over the WNP and significant divergence over the MC, is favorable for the southeasterly anomalies on the coasts of Sumatra and Java (Fig. 3a). Meanwhile, the anomalous SCSSMHC develops over the WNP and the MC. The anomalous lower-level southerly wind induced by the Coriolis force prevails from the MC to the WNP, reinforcing the anomalous southeasterly wind on the coasts of Sumatra and Java (Fig. 3a).

To illustrate the significant influence of the PMPD on the atmosphere's circulation, a similar scenario can be easily interpreted using a simple Gill model (Fig. 9). When the positive heating source over the WNP and negative heating source are taken into account (Fig. 9a), the atmospheric responses of the pressure and wind fields to the dipole heating in Fig. 9b show four remarkable features. 1) The strong southeasterly wind occurs off
Sumatra and Java; 2) the evident westerly/southwesterly wind accounts for the Bay of Bengal and SCS; 3 ) there exists a strong cyclone in the WNP; and 4) the out-ofphase pressure, the lower pressure over the WNP and the higher pressure with small amplitude over the MC, can be seen over the WNP and MC. All of those results are consistent with observations in Fig. 3. However, are the atmospheric responses similar to the observations if only considering the isolated heating over the WNP or MC? To answer this question, we take the isolated positive heating source in the MC into consideration (Fig. 9c); the atmospheric responses of the pressure and wind fields to the negative heating are displayed in Fig. 9d. Although the pronounced easterly wind component occurs off Sumatra and Java, the southeasterly wind over the Bay of Bengal and SCS, like the anticyclone in the WNP and the lack of the out-of-phase pressure are not consistent with the observations (Fig. 9d). It is suggested that it is 

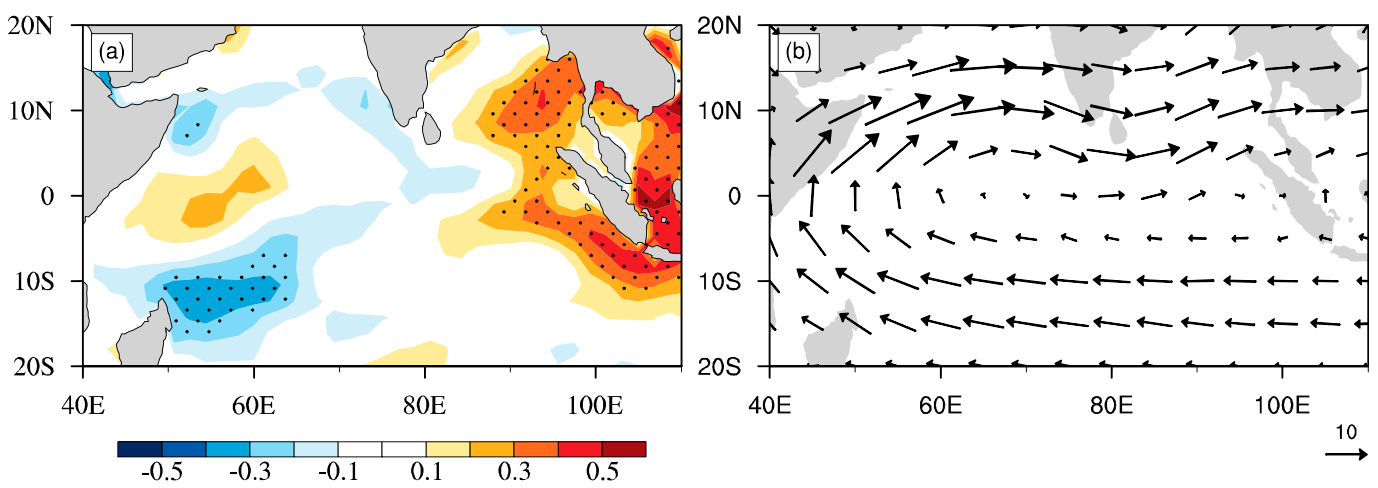

FIG. 10. (a) Correlation of the SCSSMI with the latent heat flux anomalies (shading) in JJA. A positive value indicates an upward flux, and black stipples are significant at the $95 \%$ confidence level. (b) The JJA mean climatology of the 10-m surface wind.

not enough to consider only the isolated negative heating in MC. Similarly, if the isolated positive heating source builds in the WNP (Fig. 9e), one can see in Fig. 9f that the westerly/southwesterly wind over the Bay of Bengal and SCS associated with the strong cyclone in the WNP are similar with the observations in Fig. 3, indicating the isolated positive heating over the WNP is essential to be noticed. The southeasterly wind appears along the coasts of Sumatra and Java, albeit with a lower intensity compared with Fig. 9b (Fig. 9f). In addition, the out-of-phase pressure is absent over the WNP and the MC (Fig. 9f). These imply that there are limitations in depicting the observations if considering only the isolated positive heating in the WNP. In short, the dipole heating in the WNP and MC can better depict the observational features, implying that the PMPD may affect the development of the southeasterly wind off Sumatra and Java.

Li et al. (2003) outlined that the anomalous southeasterly wind off the coasts of Sumatra and Java, as a key component of the WES and Bjerknes feedbacks, plays an important role in the development of the IOD. On the one hand, superimposed on the mean southeasterly wind in JJA (Fig. 10b), the increased southeasterly wind can enhance the excessive surface evaporation and latent heat flux loss from the ocean (Fig. 10a), causing the intensification of the negative SSTAs. The already cold SSTAs in the tropical southeastern Indian Ocean favor the enhancement of the southeasterly wind through a positive WES feedback (Xie et al. 2002; Li et al. 2003; Drbohlav et al. 2007).

On the other hand, in view of the critical role of the southeasterly wind anomalies induced by the SCSSM in the tropical southeastern Indian Ocean in the Bjerknes feedback (Bjerknes 1969; Xie et al. 2002; Ashok et al. 2003; Xiang et al. 2011; Sun et al. 2014), Fig. 11 displays the regressions of the zonal wind, meridional wind, $\mathrm{SSH}$, and SST anomalies on the SCSSMI in JJA. There exist significant anomalous southwesterly winds over the Bay of Bengal and SCS, which is consistent with the strong SCSSM case (Figs. 11a,b). Meanwhile, the significant southeasterly anomalies appear off Sumatra and Java, suggesting that they could be strengthened by the strong SCSSM (Figs. 11a,b). This is also verified by the acceleration of the southeasterly wind speed off Sumatra (not shown). Furthermore, the enhanced southeasterly wind anomalies off Sumatra and Java induced by the strong SCSSM tend to lift local thermocline anomalies through the Ekman pumping effect (Fig. 11c). The cold water from the deep ocean reinforces the cool SSTAs, leading to the increase of the zonal gradient of SSTAs in the Indian Ocean and further contributing to the growth of the IOD (Fig. 11d). These results demonstrate that the SCSSM has large contributions to the enhancement of the IOD via the Bjerknes feedback.

To depict quantificational contributions of the SCSSM to the IOD, the regression coefficients of the zonal wind with the SCSSMI (JJA DMI) area averaged over the tropical southeastern Indian Ocean region $\left(90^{\circ}-110^{\circ} \mathrm{E}\right.$, $\left.10^{\circ} \mathrm{S}-0^{\circ}\right)$ denote the mean intensity of the zonal wind explained by the SCSSM (JJA IOD). The percentage of their mean intensity (JJA IOD divided by the SCSSM) probably represents the zonal wind contribution rate of the SCSSM to the IOD. Similar conditions are suitable for the meridional wind, SSH, and SST anomalies, which are summarized in Table 2. The mean zonal wind intensity is enhanced with the magnitude about $0.26 \mathrm{~m} \mathrm{~s}^{-1}$ in the tropical southeastern Indian Ocean for the strong SCSSM, accounting for about $57 \%$ of zonal wind of the JJA IOD (Table 2). The maximum percentage with the value of $79 \%$ of the meridional wind mean intensity suggests the larger contributions of the SCSSM to the IOD in the meridional wind (Table 2). The enhanced southeasterly wind anomalies induced by the SCSSM tend to elevate the local thermocline anomalies with the 

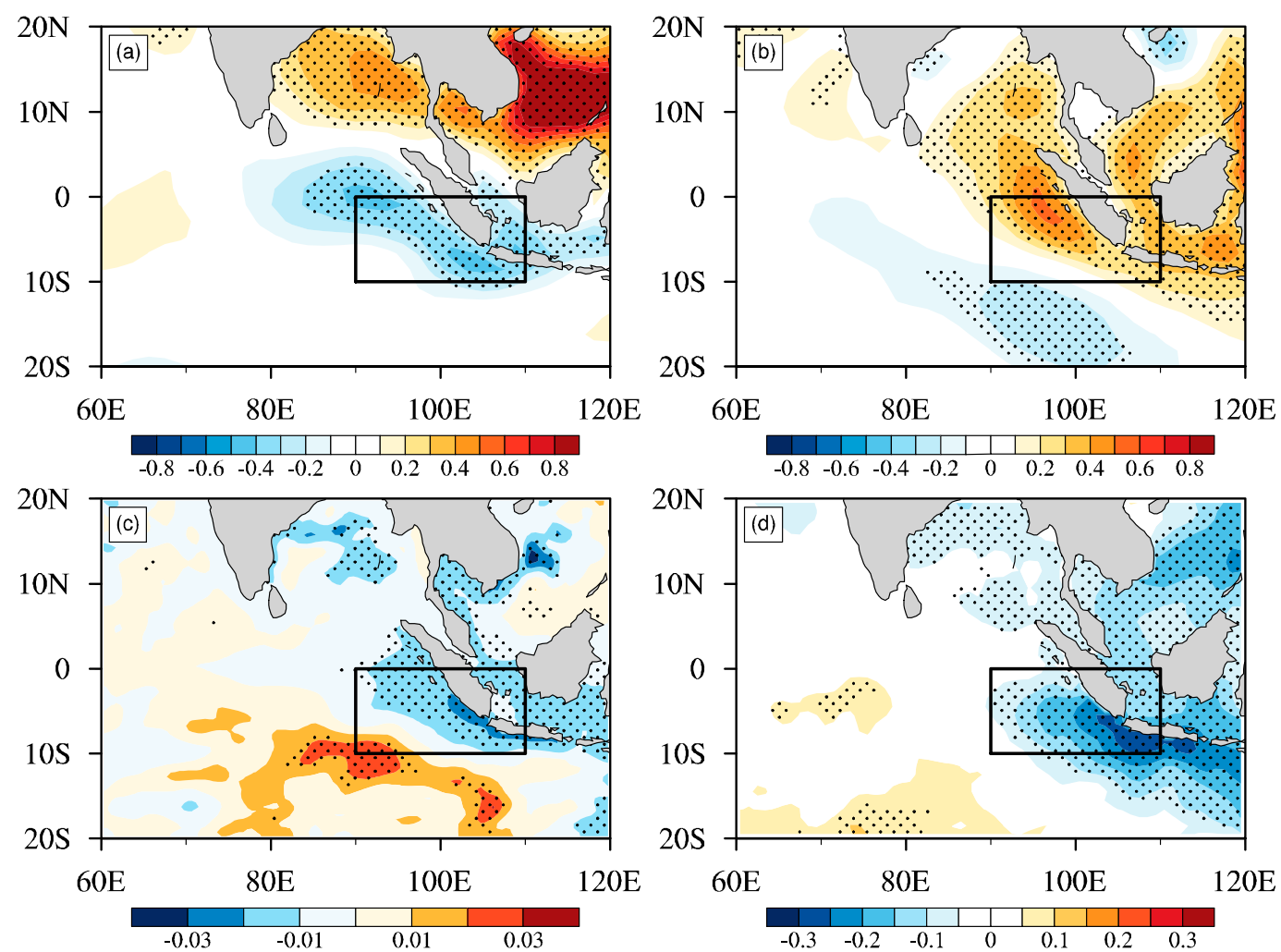

FIG. 11. Regressions of (a) 10-m surface zonal wind (shading; $\mathrm{m} \mathrm{s}^{-1}$ ), (b) meridional wind (shading; $\mathrm{m} \mathrm{s}^{-1}$ ), (c) SSH (shading; m), and (d) SSTAs (shading; ${ }^{\circ} \mathrm{C}$ ) on SCSSMI in JJA during 1948-2015. The black rectangle in (a)-(d) denotes the tropical Indian Ocean region $\left(90^{\circ}-110^{\circ} \mathrm{E}, 10^{\circ} \mathrm{S}-0^{\circ}\right)$. Black stipples in (a)-(d) indicate the $95 \%$ confidence level.

appropriate magnitude of $0.009 \mathrm{~m}$ and further contribute to the cold SSTAs $\left(-0.13^{\circ} \mathrm{C}\right)$ on the coast of Sumatra and Java. The contributions of SCSSM to the zonal wind, meridional wind, SSH, and SSTAs all exceed 57\%, suggesting the important role of the SCSSM in the enhancement of the IOD.

The observational and Gill model results demonstrate that the strong SCSSM can enhance the intensity of the southeasterly anomalies off Sumatra and Java through the PMPD and SCSSMHC, and the increased southeasterly anomalies contribute to enhancement of the cold SSTAs in the tropical southeastern Indian Ocean. The already cold SSTAs develop and are propagated westward by both the pronounced positive Bjerknes and WES feedbacks. The western pole of the IOD, in response to the eastern pole, begins to grow in JJA (Annamalai et al. 2003; Hong et al. 2008; Wang et al. 2016). Therefore, a positive IOD event develops because of the increased zonal gradient of the tropical SSTAs. Furthermore, the DMI has a peak correlation with the SCSSMI when the SCSSM leads the IOD by 3 months (Fig. 6d), indicating the delayed response of the IOD to the SCSSM. When the SCSSM is strong, the positive IOD persists from JJA to SON and reaches its mature stage within the frame of the positive Bjerknes feedback in SON and vice versa (Schott et al. 2009).

\section{Discussion}

The SCSSM is closely related to the precipitation anomalies over the WNP and MC, while Hendon (2003) indicated that Indonesia (or MC) precipitation is

TABLE 2 . The mean intensity and percentage of the 10-m surface zonal wind, meridional wind, SSH, and SST anomalies explained by the SCSSM and JJA IOD. The mean intensity of the 10-m surface zonal wind $\left(\mathrm{m} \mathrm{s}^{-1}\right)$, meridional wind $\left(\mathrm{m} \mathrm{s}^{-1}\right), \mathrm{SSH}(\mathrm{m})$, and SST $\left({ }^{\circ} \mathrm{C}\right)$ anomalies are averaged over the tropical southeastern Indian Ocean region $\left(90^{\circ}-110^{\circ} \mathrm{E}, 10^{\circ} \mathrm{S}-0^{\circ}\right)$. The percentage denotes the JJA IOD divided by the SCSSM of the zonal wind, meridional wind, wind speed, SSH, and SST anomalies.

\begin{tabular}{lccc}
\hline \hline & JJA DMI & SCSSMI & Percentage (\%) \\
\hline Zonal wind $\left(\mathrm{m} \mathrm{s}^{-1}\right)$ & -0.46 & -0.26 & 57 \\
Meridional wind $\left(\mathrm{m} \mathrm{s}^{-1}\right)$ & 0.28 & 0.22 & 79 \\
SSH $(\mathrm{m})$ & -0.015 & -0.009 & 60 \\
SST $\left({ }^{\circ} \mathrm{C}\right)$ & -0.2 & -0.13 & 65 \\
\hline
\end{tabular}



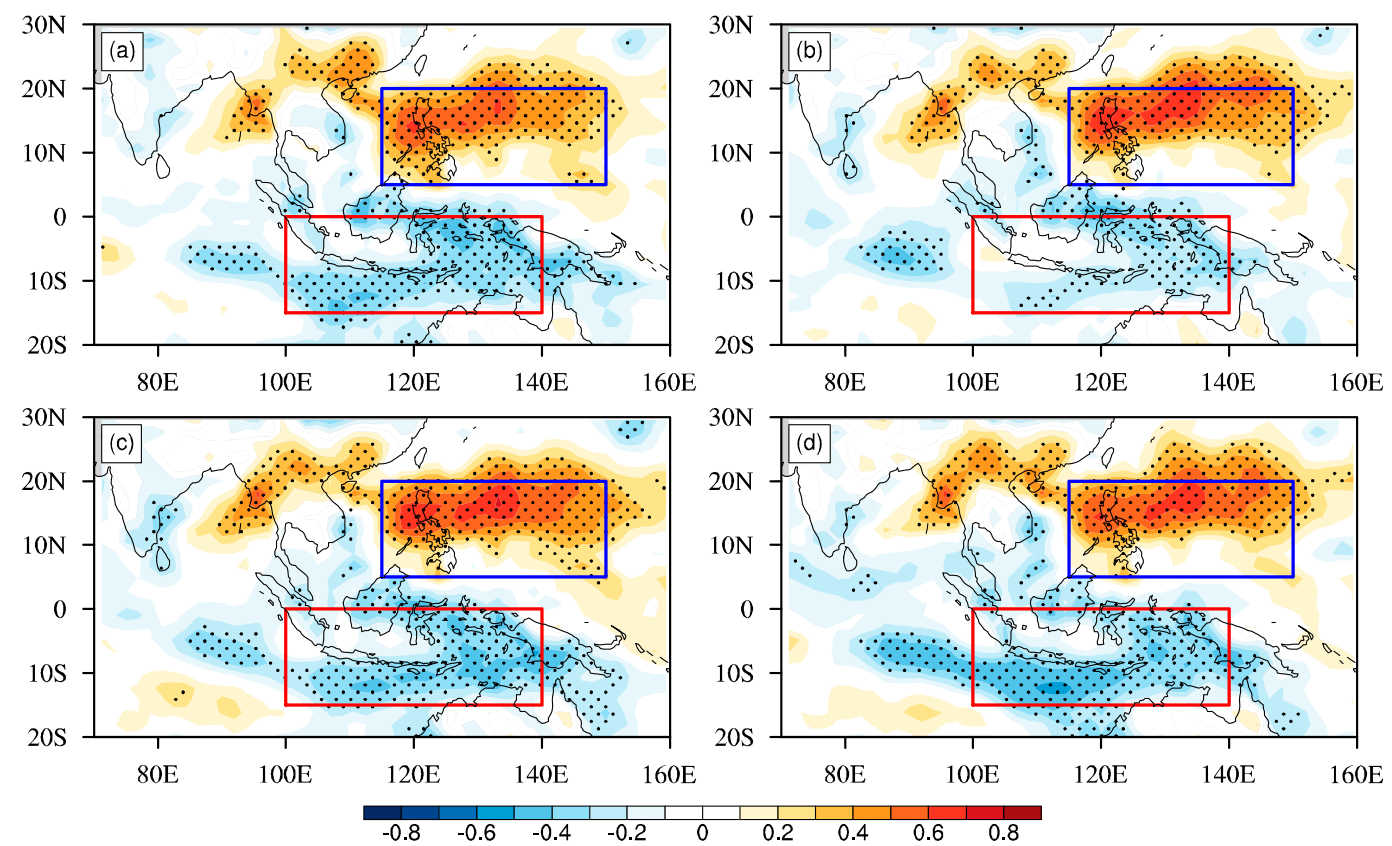

FIG. 12. Partial correlation between the SCSSMI and the precipitation anomalies after removal of the JJA (a) WNP SSTAs, (b) MC SSTAs, (c) IOD, and (d) ENSO signals. The WNP SST is defined as the area averaged over the WNP $\left(115^{\circ}-150^{\circ} \mathrm{E}, 5^{\circ}-20^{\circ} \mathrm{N}\right)$ with SSTAs [blue rectangle in (a)-(d)], MC SST as for WNP $\mathrm{SST}$, but for the $\mathrm{MC}\left(100^{\circ}-140^{\circ} \mathrm{E}, 15^{\circ} \mathrm{S}-0^{\circ}\right)$ [red rectangle in (a)-(d)]. Black stipples in (a)-(d) are significant at the $95 \%$ confidence level.

influenced by both the local and remote SSTAs in the tropical Pacific in the dry season (June-November). Do the JJA local SSTAs over the WNP and MC domains also affect the relationship between the SCSSM and the PMPD? To answer this question, Figs. 12a and $12 \mathrm{~b}$ show partial correlation maps between the SCSSMI and the precipitation anomalies over the WNP and MC after removal of the signals of the JJA WNP and MC SSTAs between 1948 and 2015. Compared with Fig. 3a, the PMPD pattern associated with the SCSSM in Fig. 12a hardly changes after removing the JJA local WNP and MC SST signal, showing the limited impacts of the JJA local WNP and MC SSTAs on the PMPD.

Apart from the local SSTAs, the precipitation anomalies over the MC are influenced by the IOD (Saji et al. 1999; Wang et al. 2016) and also modulated by ENSO (Klein et al. 1999; Hendon 2003; Kajikawa et al. 2003). The remote impacts of SSTAs in the tropical Indian and Pacific Oceans on the relationship between the SCSSM and the PMPD are also examined. To this end, the partial correlation maps between the SCSSMI and the precipitation anomalies over the WNP and the MC after removal of the signals of the JJA IOD and ENSO are shown in Figs. 12c and 12d. The PMPD pattern associated with the SCSSM over the WNP and MC barely changes after removal of the JJA IOD and ENSO signals, demonstrating the slight influence of the JJA IOD and ENSO on the relationship between the SCSSM and the PMPD in JJA (Figs. 12c,d). This pattern is similar to conditions after removing the preceding DJF and MAM local and remote SST signals (not shown). These results demonstrate the little influence of the local and remote SSTAs from the tropical Indian and Pacific Oceans on the relationship between the SCSSM and the PMPD in JJA.

In addition, Wang et al. (2016) indicated that the IOD without ENSO can be triggered by the spring Indonesia (or MC) precipitation anomalies. Meanwhile, some previous observational and modeling results suggest that the IOD is a relatively weak natural mode that can be excited by external forcing such as ENSO variability (Xie et al. 2002; Annamalai et al. 2003; Schott et al. 2009; Wang and Wang 2014; Guo et al. 2015; Yang et al. 2015; Stuecker et al. 2017). Hence, it is important to assess the influence of ENSO on the relationship between the IOD and the SCSSM. For this purpose, Table 1 shows the partial correlation of the SCSSMI with JJA and SON DMI after the removal of the preceding DJF, MAM, and JJA ENSO signals for the period of 1948-2015. The correlation coefficient between the SCSSMI and JJA DMI is 0.46 , and this falls to 0.4 (still significant at the 99\% level) after removal of the JJA ENSO signal; that is, it barely changes even after removing the signals of the preceding DJF and MAM ENSO (Table 1). The 

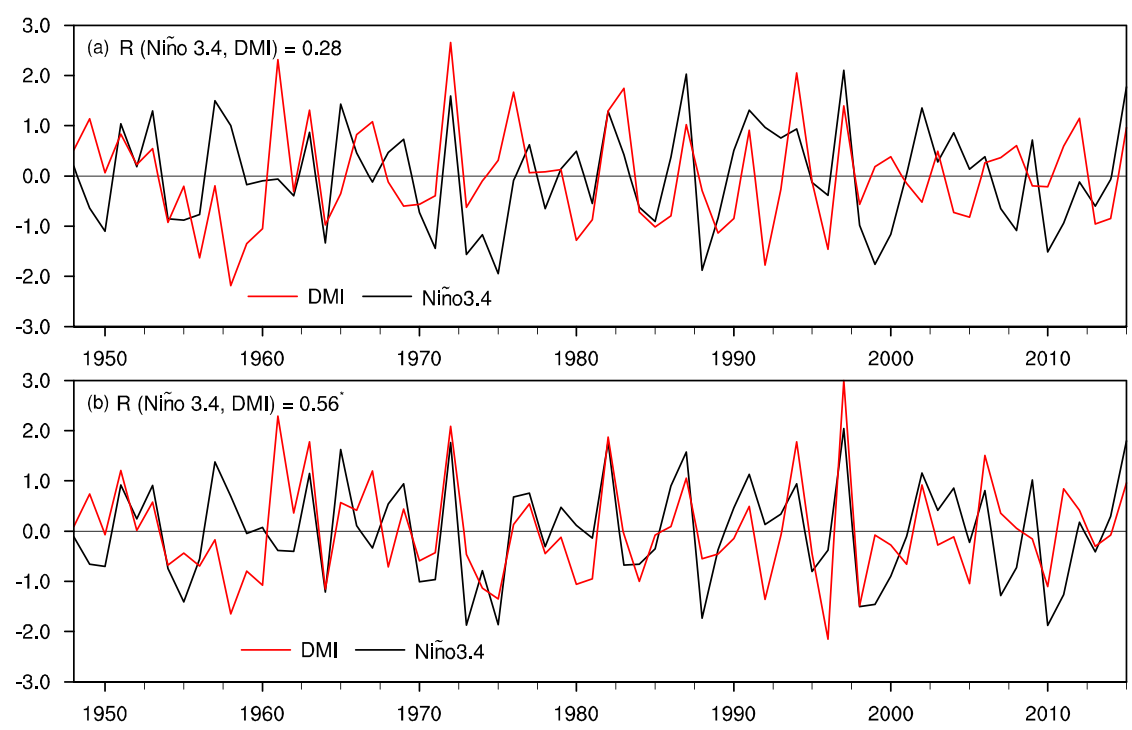

FIG. 13. Time series of standardized Niño-3.4 (black line) with DMI (red line) in (a) JJA and (b) SON for the period of 1948-2015. The correlation coefficient $R$ with the asterisk indicates the $99 \%$ confidence level.

correlation coefficient between the JJA DMI and JJA Niño-3.4 (0.28) is also not significant, as shown in Fig. 13a, which indicates a weak relationship between the IOD and ENSO in JJA. Except for JJA, the partial correlation coefficient between the SCSSMI and SON DMI is still significant after removal of the preceding DJF, MAM, and JJA ENSO signals (Table 1). These results indicate that the SCSSM is significantly correlated with the IOD in JJA and SON, even though ENSO can slightly weaken the relationship between the IOD and the SCSSM. However, we note that the relationship between the SON DMI and SON Niño-3.4 is significant, with a value of 0.56 (significant at the $99 \%$ level), showing the close relationship between ENSO and the IOD in SON (Fig. 13b). The relative contributions of the SCSSM and ENSO to the IOD require further study.

\section{Summary}

In this study, we investigated the impact of the SCSSM on the IOD in JJA and the relevant physical mechanisms. For a strong SCSSM event, the enhanced southwesterly wind over the Bay of Bengal and SCS that brings more moisture to the WNP leads to surplus precipitation over the WNP, inducing the anomalous ascending motion there. Consequently, the anomalous descending motion of the SCSSMHC develops over the $\mathrm{MC}$, contributing to deficit precipitation in the MC. With the increased gradient of the precipitation anomalies over the WNP and MC, the lower-level southwesterly wind is strengthened, which suggests the enhancement of SCSSM. The enhanced SCSSM further promotes the development of the SCSSMHC and PMPD. According to the asymmetric Gill theory (Gill 1980), the PMPD contributes to the intensification of the southeasterly wind anomalies off the coasts of Sumatra and Java. On one hand, the increased southeasterly wind anomalies enhance the excessive surface evaporation and latent heat loss from the ocean, leading to the development of the negative SSTAs in the tropical southeastern Indian Ocean via the positive WES feedback. On the other hand, the increased southeasterly wind anomalies induce coastal upwelling off Sumatra and Java via the Ekman pumping effect, causing an increase in the cold SSTAs in the tropical southeastern Indian Ocean through the positive Bjerknes feedback. Consequently, a positive IOD event develops in JJA because of the increased zonal gradient of the tropical SSTAs and vice versa. In addition, the IOD has a delayed response to the SCSSM by 3 months, demonstrating that the SCSSM affects the development of the SON IOD. This implies that the positive IOD persists from JJA to SON and reaches its mature phase within the frame of the positive Bjerknes feedback in SON. These results indicate that the SCSSM has a significant impact on the IOD through the anomalous PMPD and SCSSMHC. The relevant processes of the SCSSM affecting the IOD are shown schematically in Fig. 14.

Some earlier studies addressed the impact of the IOD on the Asian monsoon or the East Asian climate (Ashok et al. 2001; Guan and Yamagata 2003; Ding et al. 2008), while the PMPD associated with the SCSSM between 


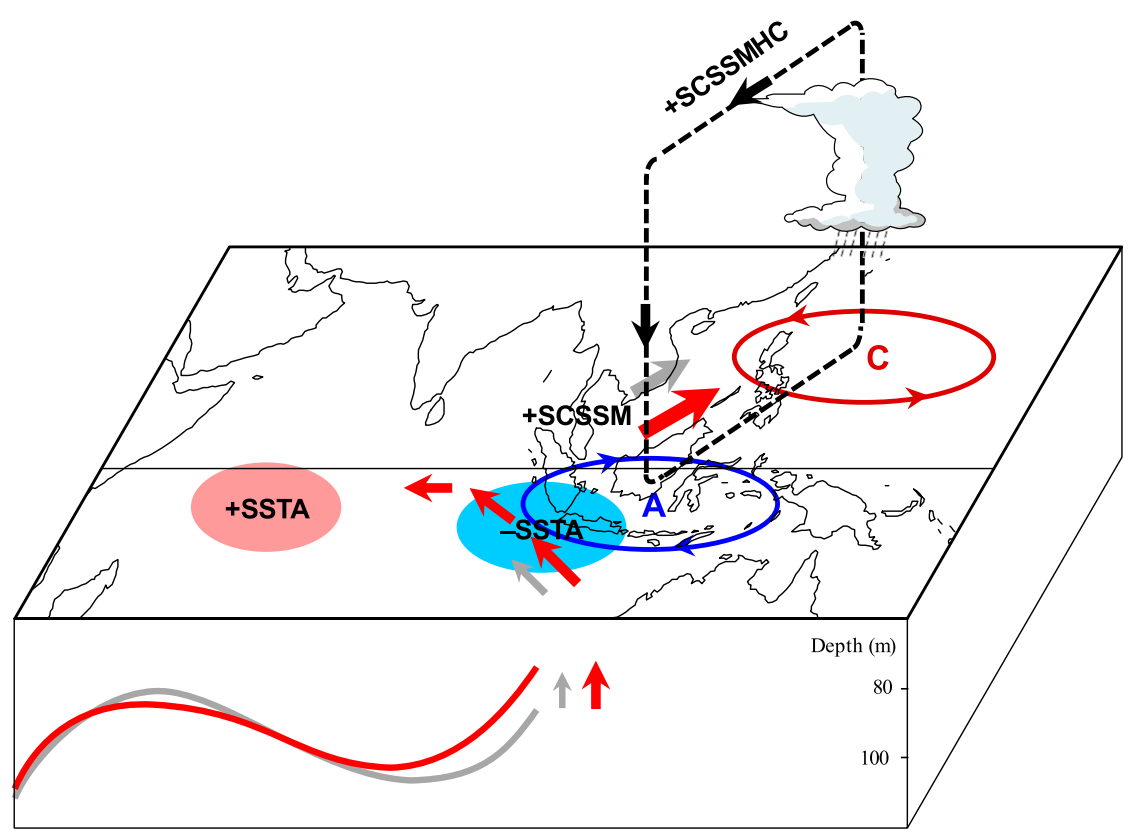

FIG. 14. Schematic diagram of the SCSSM affecting the IOD. The + indicates the significant positive SSTAs, strong SCSSM, or enhanced SCSSMHC, and - indicates the negative SSTAs. The gray vectors and curve represent the mean climatology, and the red vectors and curve represent the condition for the strong SCSSM. The cloud with the short dotted line indicates the positive precipitation anomalies in the WNP, and the black circulation line with the black vectors denotes the SCSSMHC. The red (blue) elliptic circle with the arrows denotes the anomalous cyclone (C) or anticyclone (A).

the WNP and the MC is barely affected by the local and remote SSTAs in the tropical Indian and Pacific Oceans. Although ENSO has little impact on the relationship between the SCSSM and JJA IOD, the high correlation (0.56) of the IOD with ENSO exists in SON, suggesting that ENSO has large contributions to the maturation of the IOD. While the contributions of the SCSSM are larger in SON than JJA, the relative contributions of the SCSSM and ENSO to the maturation of the IOD need to be further studied. In addition, given the interaction between the monsoon and the IOD, it is not only better to understand the IOD development, but also to capture the Asian summer monsoon easily (Swapna and Krishnan 2008; Krishnan and Swapna 2009; Krishnan et al. 2011). Further experiments using atmospheric and oceanic models, extended in scope, are also needed to better understand the relationship between the SCSSM and the IOD.

Acknowledgments. This work was jointly supported by the National Natural Science Foundation of China (NSFC) Project (41530424), SOA International Cooperation Program on Global Changes and Air-Sea Interactions (GASI-IPOVAI-03), and the Fundamental Research Funds for the Central Universities.

\section{REFERENCES}

Annamalai, H., R. Murtugudde, J. Potemra, S. P. Xie, P. Liu, and B. Wang, 2003: Coupled dynamics over the Indian Ocean: Spring initiation of the zonal mode. Deep-Sea Res. II, 50, 23052330, https://doi.org/10.1016/S0967-0645(03)00058-4.

Ashok, K., Z. Guan, and T. Yamagata, 2001: Impact of the Indian Ocean dipole on the relationship between the Indian monsoon rainfall and ENSO. Geophys. Res. Lett., 28, 4499-4502, https:// doi.org/10.1029/2001GL013294.

,-- , and 2003: A look at the relationship between the ENSO and the Indian Ocean dipole. J. Meteor. Soc. Japan, 81, 41-56, https://doi.org/10.2151/jmsj.81.41.

Behera, S. K., R. Krishnan, and T. Yamagata, 1999: Unusual oceanatmosphere conditions in the tropical Indian Ocean during 1994. Geophys. Res. Lett., 26, 3001-3004, https://doi.org/10.1029/ 1999GL010434.

_ J. J. Luo, S. Masson, S. A. Rao, H. Sakuma, and T. Yamagata, 2006: A CGCM study on the interaction between IOD and ENSO. J. Climate, 19, 1688-1705, https://doi.org/10.1175/JCLI3797.1.

Bjerknes, J., 1969: Atmospheric teleconnections from the equatorial Pacific. Mon. Wea. Rev., 97, 163-172, https://doi.org/10.1175/ 1520-0493(1969)097<0163:ATFTEP>2.3.CO;2.

Carton, J. A., and B. S. Giese, 2008: A reanalysis of ocean climate using Simple Ocean Data Assimilation (SODA). Mon. Wea. Rev., 136, 2999-3017, https://doi.org/10.1175/2007MWR1978.1.

Ding, R., J. Li, and K.-J. Ha, 2008: Decadal change of January and July persistence of monthly mean $500 \mathrm{hPa}$ geopotential height anomalies. Geophys. Res. Lett., 35, L15702, https://doi.org/ 10.1029/2008GL034137. 
Drbohlav, H.-K. L., S. Gualdi, and A. Navarra, 2007: A diagnostic study of the Indian Ocean dipole mode in El Niño and non-El Niño years. J. Climate, 20, 2961-2977, https://doi.org/10.1175/ JCLI4153.1.

Fan, L., Q. Liu, C. Wang, and F. Guo, 2017: Indian Ocean dipole modes associated with different types of ENSO development. J. Climate, 30, 2233-2249, https://doi.org/10.1175/ JCLI-D-16-0426.1.

Feng, J., J. Li, Y. Li, J. Zhu, and F. Xie, 2015: Relationships among the monsoon-like southwest Australian circulation, the southern annular mode, and winter rainfall over southwest western Australia. Adv. Atmos. Sci., 32, 1063-1076, https://doi.org/ 10.1007/s00376-014-4142-z.

Feng, M., and G. Meyers, 2003: Interannual variability in the tropical Indian Ocean: A two-year time-scale of Indian Ocean dipole. Deep-Sea Res. II, 50, 2263-2284, https://doi.org/10.1016/ S0967-0645(03)00056-0.

Fischer, A. S., P. Terray, E. Guilyardi, S. Gualdi, and P. Delecluse, 2005: Two independent triggers for the Indian Ocean dipole/ zonal mode in a coupled GCM. J. Climate, 18, 3428-3449, https://doi.org/10.1175/JCLI3478.1.

Gill, A. E., 1980: Some simple solutions for heat-induced tropical circulation. Quart. J. Roy. Meteor. Soc., 106, 447-462, https:// doi.org/10.1002/qj.49710644905.

Grunseich, G., B. Subrahmanyam, V. S. N. Murty, and B. S. Giese, 2011: Sea surface salinity variability during the Indian Ocean dipole and ENSO events in the tropical Indian Ocean. J. Geophys. Res., 116, C11013, https://doi.org/10.1029/2011JC007456.

Guan, Z., and T. Yamagata, 2003: The unusual summer of 1994 in East Asia: IOD teleconnections. Geophys. Res. Lett., 30, 1544, https://doi.org/10.1029/2002GL016831.

Guo, F., Q. Liu, S. Sun, and J. Yang, 2015: Three types of Indian Ocean dipoles. J. Climate, 28, 3073-3092, https://doi.org/10.1175/ JCLI-D-14-00507.1.

Hendon, H. H., 2003: Indonesian rainfall variability: Impacts of ENSO and local air-sea interaction. J. Climate, 16, 1775-1790, https:// doi.org/10.1175/1520-0442(2003)016<1775:IRVIOE > 2.0.CO;2.

Hong, C.-C., M.-M. Lu, and M. Kanamitsu, 2008: Temporal and spatial characteristics of positive and negative Indian Ocean dipole with and without ENSO. J. Geophys. Res., 113, D08107, https://doi.org/10.1029/2007JD009151.

Huyan, L., J. Li, S. Zhao, C. Sun, D. Dong, T. Liu, and Y. Zhao, 2017: The impact of layer perturbation potential energy on the East Asian summer monsoon. J. Climate, 30, 7087-7103, https://doi.org/10.1175/JCLI-D-16-0729.1.

Kajikawa, Y., T. Yasunari, and R. Kawamura, 2003: The role of the local Hadley circulation over the western Pacific on the zonally asymmetric anomalies over the Indian Ocean. J. Meteor. Soc. Japan, 81, 259-276, https://doi.org/10.2151/jmsj.81.259.

Kalnay, E., and Coauthors, 1996: The NCEP/NCAR 40-Year Reanalysis Project. Bull. Amer. Meteor. Soc., 77, 437-471, https:// doi.org/10.1175/1520-0477(1996)077<0437:TNYRP>2.0.CO;2.

Klein, S. A., B. J. Soden, and N.-C. Lau, 1999: Remote sea surface temperature variations during ENSO: Evidence for a tropical atmospheric bridge. J. Climate, 12, 917-932, https://doi.org/ 10.1175/1520-0442(1999)012<0917:RSSTVD>2.0.CO;2.

Krishnan, R., and P. Swapna, 2009: Significant influence of the boreal summer monsoon flow on the Indian Ocean response during dipole events. J. Climate, 22, 5611-5634, https://doi.org/ 10.1175/2009JCLI2176.1.

, S. Sundaram, P. Swapna, V. Kumar, D. C. Ayantika, and M. Mujumdar, 2011: The crucial role of ocean-atmosphere coupling on the Indian monsoon anomalous response during dipole events. Climate Dyn., 37, 1-17, https://doi.org/10.1007/ s00382-010-0830-2.

Lau, N.-C., and M. J. Nath, 2004: Coupled GCM simulation of atmosphere-ocean variability associated with zonally asymmetric SST changes in the tropical Indian Ocean. J. Climate, 17, 245-265, https://doi.org/10.1175/1520-0442(2004)017<0245: CGSOAV $>2.0 . \mathrm{CO} ; 2$.

Li, C., and M. Mu, 2001: The influence of the Indian Ocean dipole on atmospheric circulation and climate. Adv. Atmos. Sci., 18, 831-843.

Li, J., and Q. Zeng, 2002: A unified monsoon index. Geophys. Res. Lett., 29, 1274, https://doi.org/10.1029/2001GL013874.

- , and _ 2003: A new monsoon index and the geographical distribution of the global monsoons. Adv. Atmos. Sci., 20, 299302, https://doi.org/10.1007/s00376-003-0016-5.

_ _ Z. Wu, Z. Jiang, and J. He, 2010: Can global warming strengthen the East Asian summer monsoon? J. Climate, 23, 6696-6705, https://doi.org/10.1175/2010JCLI3434.1.

_ G. X. Wu, and D. X. Hu, 2011a: Ocean-Atmosphere Interaction over the Joining Area of Asia and Indian-Pacific Ocean and Its Impact on the Short-Term Climate Variation in China (in Chinese). Vol. 1. China Meteorological Press, $516 \mathrm{pp}$.

,-- , and $-2011 \mathrm{~b}$ : Ocean-Atmosphere Interaction over the Joining Area of Asia and Indian-Pacific Ocean and Its Impact on the Short-Term Climate Variation in China (in Chinese). Vol. 2. China Meteorological Press, 565 pp.

Li, T., B. Wang, C.-P. Chang, and Y. Zhang, 2003: A theory for the Indian Ocean dipole-zonal mode. J. Atmos. Sci., 60, 2119-2135, https://doi.org/10.1175/1520-0469(2003)060<2119: ATFTIO $>2.0 . \mathrm{CO} ; 2$.

Liu, T., J. Li, Y. Li, S. Zhao, F. Zheng, J. Zheng, and Z. Yao, 2018: Influence of the May southern annular mode on the South China Sea summer monsoon. Climate Dyn., https://doi.org/ 10.1007/s00382-017-3753-3, in press.

Masson, S., J.-P. Boulanger, C. Menkes, P. Delecluse, and T. Yamagata, 2004: Impact of salinity on the 1997 Indian Ocean dipole event in a numerical experiment. J. Geophys. Res., 109, C02002, https://doi.org/10.1029/2003JC001807.

Nuncio, M., and X. Yuan, 2015: The influence of the Indian Ocean dipole on Antarctic sea ice. J. Climate, 28, 2682-2690, https:// doi.org/10.1175/JCLI-D-14-00390.1.

Rayner, N. A., D. E. Parker, E. B. Horton, C. K. Folland, L. V. Alexander, D. P. Rowell, E. C. Kent, and A. Kaplan, 2003: Global analyses of sea surface temperature, sea ice, and night marine air temperature since the late nineteenth century. J. Geophys. Res., 108, 4407, https://doi.org/10.1029/2002JD002670

Saji, N. H., and T. Yamagata, 2003: Structure of SST and surface wind variability during Indian Ocean dipole mode events: COADS observations. J. Climate, 16, 2735-2751, https://doi.org/ 10.1175/1520-0442(2003)016<2735:SOSASW $>2.0 . \mathrm{CO} ; 2$

_ B. N. Goswami, P. N. Vinayachandran, and T. Yamagata, 1999: A dipole mode in the tropical Indian Ocean. Nature, 401, 360-363, https://doi.org/10.1038/43854.

Schott, F. A., S.-P. Xie, and J. P. McCreary Jr., 2009: Indian Ocean circulation and climate variability. Rev. Geophys., 47, RG1002, https://doi.org/10.1029/2007RG000245.

Shinoda, T., H. H. Hendon, and M. A. Alexander, 2004: Surface and subsurface dipole variability in the Indian Ocean and its relation with ENSO. Deep-Sea Res. I, 51, 619-635, https:// doi.org/10.1016/j.dsr.2004.01.005.

Spencer, H., R. T. Sutton, J. M. Slingo, M. Roberts, and E. Black, 2005: Indian Ocean climate and dipole variability in Hadley 
Centre coupled GCMs. J. Climate, 18, 2286-2307, https://doi.org/ 10.1175/JCLI3410.1.

Stuecker, M. F., A. Timmermann, F.-F. Jin, Y. Chikamoto, W. Zhang, A. T. Wittenberg, E. Widiasih, and S. Zhao, 2017: Revisiting ENSO/Indian Ocean dipole phase relationships. Geophys. Res. Lett., 44, 2481-2492, https://doi.org/10.1002/ 2016 GL072308.

Sun, S., Y. Fang, Tana, and B. Liu, 2014: Dynamical mechanisms for asymmetric SSTA patterns associated with some Indian Ocean dipoles. J. Geophys. Res., 119, 3076-3097, https://doi.org/ 10.1002/2013JC009651.

Swapna, P., and R. Krishnan, 2008: Equatorial undercurrents associated with Indian Ocean dipole events during contrasting summer monsoons. Geophys. Res. Lett., 35, L14S04, https:// doi.org/10.1029/2008GL033430.

Wang, B., F. Huang, Z. Wu, J. Yang, X. Fu, and K. Kikuchi, 2009: Multi-scale climate variability of the South China Sea monsoon: A review. Dyn. Atmos. Oceans, 47, 15-37, https://doi.org/ 10.1016/j.dynatmoce.2008.09.004.

Wang, H., R. Murtugudde, and A. Kumar, 2016: Evolution of Indian Ocean dipole and its forcing mechanisms in the absence of ENSO. Climate Dyn., 47, 2481-2500, https://doi.org/10.1007/ s00382-016-2977-y.

Wang, X., and C. Wang, 2014: Different impacts of various El Niño events on the Indian Ocean dipole. Climate Dyn., 42, 9911005, https://doi.org/10.1007/s00382-013-1711-2.

Webster, P. J., A. M. Moore, J. P. Loschnigg, and R. R. Leben, 1999: Coupled ocean-atmosphere dynamics in the Indian Ocean during 1997-98. Nature, 401, 356-360, https://doi.org/ $10.1038 / 43848$.

Xiang, B., W. Yu, T. Li, and B. Wang, 2011: The critical role of the boreal summer mean state in the development of the IOD. Geophys. Res. Lett., 38, L02710, https://doi.org/10.1029/2010GL045851.
Xie, P., and P. A. Arkin, 1997: Global precipitation: A 17-year monthly analysis based on gauge observations, satellite estimates, and numerical model outputs. Bull. Amer. Meteor. Soc., 78, 2539-2558, https://doi.org/10.1175/1520-0477(1997)078<2539: GPAYMA $>2.0 . C O ; 2$.

Xie, S.-P., H. Annamalai, F. A. Schott, and J. P. McCreary Jr., 2002: Structure and mechanisms of south Indian Ocean climate variability. J. Climate, 15, 864-878, https://doi.org/10.1175/ 1520-0442(2002)015<0864:SAMOSI >2.0.CO;2.

Xing, N., J.-P. Li, and Y.-K. Li, 2014: A theoretical explanation of anomalous atmospheric circulation associated with ENSO Modoki during boreal winter. Atmos. Ocean. Sci. Lett., 7, 352357, https://doi.org/10.3878/j.issn.1674-2834.14.0020.

Yang, J., Q. Liu, and Z. Liu, 2010: Linking observations of the Asian monsoon to the Indian Ocean SST: Possible roles of Indian Ocean basin mode and dipole mode. J. Climate, 23, 5889-5902, https://doi.org/10.1175/2010JCLI2962.1.

Yang, Y., S.-P. Xie, L. Wu, Y. Kosaka, N.-C. Lau, and G. A. Vecchi, 2015: Seasonality and predictability of the Indian Ocean dipole mode: ENSO forcing and internal variability. J. Climate, 28, 8021-8036, https://doi.org/10.1175/ JCLI-D-15-0078.1.

Yuan, Y., H. Yang, W. Zhou, and C. Li, 2008: Influences of the Indian Ocean dipole on the Asian summer monsoon in the following year. Int. J. Climatol., 28, 1849-1859, https://doi.org/ 10.1002/joc.1678.

Zhang, Y., Y. Du, and T. Qu, 2016: A sea surface salinity dipole mode in the tropical Indian Ocean. Climate Dyn., 47, 25732585, https://doi.org/10.1007/s00382-016-2984-z.

Zhu, J., H. Liao, and J. Li, 2012: Increases in aerosol concentrations over eastern China due to the decadal-scale weakening of the East Asian summer monsoon. Geophys. Res. Lett., 39, L09809, https://doi.org/10.1029/2012GL051428. 